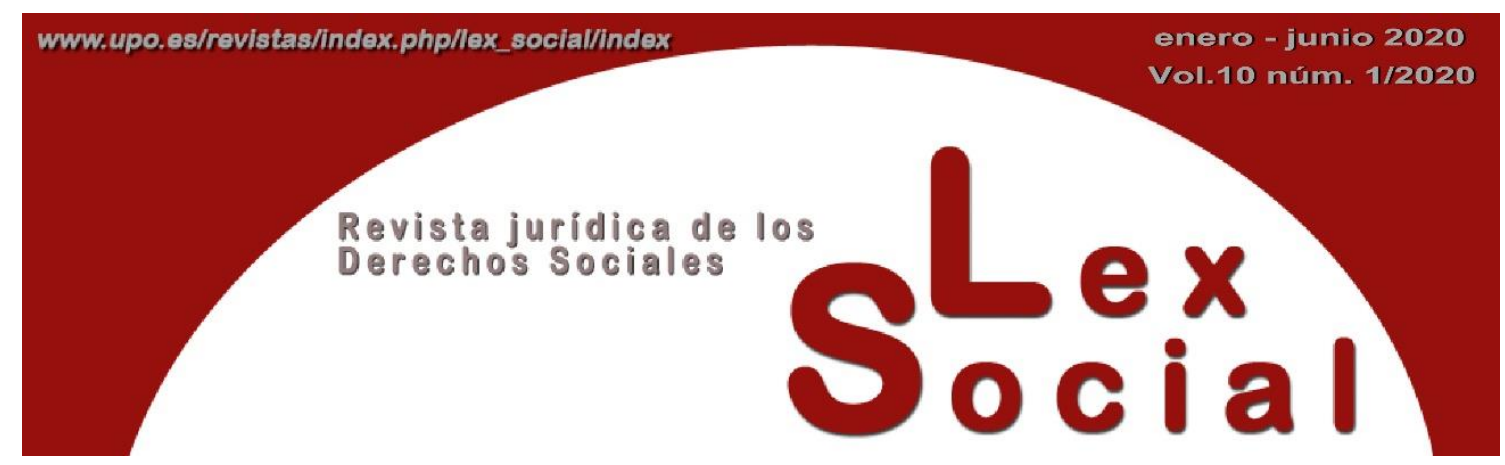

\title{
EL PAPEL DEL DEFENSOR DEL PUEBLO DESTACANDO LA IMPORTANCIA DE LOS SEGUROS DE SALUD PRIVADOS PARA EL DERECHO A LA PROTECCIÓN DE LA SALUD DE LAS PERSONAS CON DISCAPACIDAD
}

\section{THE ROLE OF THE OMBUDSMAN HIGHLIGHTING THE RELATIONSHIP BETWEEN PRIVATE HEALTH INSURANCE AND THE RIGHT TO HEALTH PROTECTION OF PERSONS WITH DISABILITIES}

MARÍA DEL VAL BOLIVAR OÑORO

Personal Docente e Investigador en Formación (FPU)

Universidad de Alcalá

Artículo recibido el 5 de septiembre de 2019

Artículo aceptado el 3 de noviembre de 2019

\section{RESUMEN}

Esta contribución hace un breve repaso al derecho a la protección de la salud en España, poniendo de relieve las dificultades que han surgido en torno a él a raíz del Real Decreto-Ley 16/2012. Dificultades que se traducen en la posibilidad de no poder acceder de manera gratuita a determinados procedimientos o tratamientos en el futuro, acentuando esta situación el hecho de que la discapacidad sea un obstáculo para que muchas personas aminoren este riesgo con un seguro de salud privado. El Defensor del Pueblo desde finales del Siglo XX venía haciéndose eco de las barreras que las personas con discapacidad encuentran para acceder a los seguros de salud privados y del rol que estos tienen en el derecho a la protección de la salud contemplado en el artículo 43 de la Constitución. Sin embargo, no ha sido hasta 2011 y 2018 cuando se han producido avances legislativos en esta materia.

Palabras Clave: derechos de las personas discapacidad, seguros de salud, derecho a la protección de la salud, defensor del pueblo. 


\begin{abstract}
This paper briefly reviews the Right to Protection of Health in Spain, highlighting the difficulties that have arisen following the Royal Decree-Law 16/2012. These issues could make people feel at risk when it comes to coverage of their medical treatments by the National Healthcare System. Therefore, some would think about purchasing private health insurance to ameliorate that risk. However, persons with disabilities face barriers in the contracting process. The Spanish Ombudsman had been long echoing these barriers and the relationship of this product along with the Right to Protection of Health referred to in article 43 of the Constitution. Nevertheless, it has not been until 2011 and 2018 when these barriers started to disappear.
\end{abstract}

KEYWORDS: rights of persons with disabilities, private health insurance, right to protection of health, ombudsperson.

SUMARIO

1. Introducción

2. La importancia de los seguros privados en la protección de la salud

3. Seguros de asistencia sanitaria y discapacidad

3.1. Una cuestión que sobrepasa nuestras fronteras

3.2. La preocupación por la materia: El rol del Defensor del Pueblo

4. Conclusiones

5. Bibliografía

\title{
1. Introducción
}

Después de haber caminado durante más de treinta años hacia la asistencia sanitaria universal gratuita, sea por lo que fuere, en 2012 esta tendencia se corta, lo que no solo hizo tambalearse la atribución de competencias entre el Estado y las Comunidades Autónomas, sino que también generaría preocupación en la población. Preocupación por la existencia de un riesgo, que lleva a las personas al deseo de eliminarlo, habiéndose demostrado el seguro como uno de los instrumentos más eficaces para esta tarea. Siendo este peligro el de encontrarse ante la falta de cobertura de un procedimiento o tratamiento médico, el seguro de asistencia sanitaria sería el instrumento adecuado para aminorarlo o eliminarlo. La cuestión es ¿pueden todas las personas acceder a los seguros de salud privados? En el ámbito internacional es un hecho conocido de largo que las personas con discapacidad encuentran barreras para acceder a este producto, muestra de ello es la 
mención en la Convención sobre los Derechos de las Personas con Discapacidad y la Agenda 2030. En España, el Defensor del Pueblo plasmaría ya una queja sobre la materia en su Informe Anual para el año 1999, queja que fue sucedida por muchas y convertida en sugerencia por el Defensor del Pueblo Navarro en 2010. Actuación esta última que daría como resultado una modificación legislativa que, si bien no puede ser leída como definitiva, camina en la dirección adecuada. Situación que nos hace valorar el rol del Defensor del Pueblo en la mejor garantía del derecho a la protección de la salud consagrado en el artículo 43 de la Constitución y en la consecución de los objetivos de derechos humanos plasmados en la Agenda 2030.

Con todo ello, para proceder al análisis de tan concreta cuestión, la siguiente contribución aportará unas breves notas sobre el derecho a la protección de la salud en los últimos tiempos para poder apreciar mejor la relevancia de los seguros privados de salud en el marco del derecho contemplado en el artículo 43 de la Constitución. Una vez finalizada esta referencia, nos focalizamos en el asunto central aquí debatido, las barreras que las personas con discapacidad encuentran en el acceso a los seguros de salud privados y el rol que los defensores del pueblo han jugado en la eliminación de algunos de estos obstáculos.

\section{La importancia de los seguros privados en la protección de salud}

El derecho a la protección de la salud está recogido en el artículo 43 de la Constitución Española de 1978 -en adelante CE- como sigue:

"1. Se reconoce el derecho a la protección de la salud.

2. Compete a los poderes públicos organizar y tutelar la salud pública a través de medidas preventivas y de las prestaciones y servicios necesarios. La ley establecerá los derechos y deberes de todos al respecto.

3. Los poderes públicos fomentarán la educación sanitaria, la educación física y el deporte. Asimismo, facilitarán la adecuada utilización del ocio."

De acuerdo con su tenor literal, podría pasar sin más como "hermano" del derecho a la educación contenido en el artículo 27 de la $\mathrm{CE}$, pero es precisamente esto, el número, su ubicación dentro de la CE, lo que les hace definitivamente diferentes. A diferencia del derecho a la educación que se sitúa en la Sección Primera del Capítulo Segundo del Título I de la CE, el derecho a la protección de la salud se ubica en el Capítulo Tercero del Título I de la CE, ubicaciones de las que ya solo los nombres "De los derechos fundamentales y de las libertades públicas" para el primero y "De los principios rectores de la política social y económica" para el segundo, podrían hacer temer lo que el artículo $53 \mathrm{CE}$ fija. De acuerdo con lo dispuesto en el artículo 53.1 CE, los derechos contenidos en el Capítulo Segundo del Título I de la CE solo podrán ser regulados por ley -reserva de ley- y las leyes que los desarrollen deberán respetar su contenido esencial. Además, el artículo 53.2 CE establece que se podrá recabar la tutela de las libertades y derechos reconocidos en el 
artículo 14 de la CE y la Sección primera del Capítulo Segundo del Título I de la CE ante los Tribunales ordinarios por un procedimiento preferente y sumario y, en su caso, a través del recurso de amparo ante el Tribunal Constitucional -en adelante TC-. Sin embargo, respecto a los derechos contenidos en el Capítulo Tercero del Título I de la CE el artículo 53.3 de la CE solo prevé la posibilidad de ser alegados ante la Jurisdicción ordinaria de acuerdo con lo que dispongan las leyes que los desarrollen y su función como informadores de la legislación positiva.

Esta división tripartita ${ }^{1}$ generaría el debate en torno a cuáles son los derechos que la CE reconoce como fundamentales. En un primer momento, la previsión del artículo 53.2 CE hizo defender un concepto extremadamente estricto que calificaría como únicos derechos fundamentales aquellos contenidos en los artículos 14 a 29 de la $\mathrm{CE}^{2}$, pero pronto se llegaría a la conclusión de que "ni las diferencias existentes en cuanto a las vías procesales para la defensa de los derechos, ni las que afectan a las condiciones exigidas para la reforma de los enunciados que los consagran, quiebran la unidad de la clase integrada por todos los derechos que la Constitución otorga a los ciudadanos directamente, sustrayéndolos a la libertad del legislador, el cual, con independencia de que su intermediación pueda ser necesaria para el ejercicio de los derechos, ha de respetar su existencia y su contenido mínimo" 3 . Si se entendiese de otro modo se llegaría entre otras a la conclusión de que en aquellos países que no tienen recurso amparo por violación de derechos fundamentales ante el TC, como Italia o Francia, no existen derechos fundamentales, conclusión que no puede sino ser calificada de errónea ${ }^{4}$. Por lo tanto, parece hoy admitido por una doctrina mayoritaria que todos los derechos y libertades del Capítulo II del Título I de la CE son derechos fundamentales, pues concurren en ellos dos rasgos que los identifican como tales: la vinculación de todos los poderes públicos y en especial del legislador ${ }^{5}$ y la tutela directa ( $\sin$ esperar al desarrollo legislativo) ${ }^{6}$. Sin embargo, afirmando que solo los anteriores son derechos fundamentales, se produce el efecto automático de negación del mismo estatus a los derechos contenidos en el Capítulo III $^{7}$. Es decir, acogiendo esta teoría estaríamos afirmando que pese a que el derecho a la

\footnotetext{
${ }^{1}$ Prieto Sanchís, L. (1990). Estudios sobre derechos fundamentales. Debate. pp. 103-109.

${ }^{2}$ Martín-Retortillo Baquer, L., de Otto, Ignacio. (1988). Derechos fundamentales y Constitución. Civitas. pp. 65 y ss.

${ }^{3}$ Rubio Llorente, F. (1997). "Los derechos fundamentales. Evolución, fuentes y titulares en España". Claves de Razón práctica. p. 3.

${ }^{4}$ Escobar Roca, G. (2018). Nuevos derechos y garantías de los derechos. Marcial Pons. p.26.

${ }^{5}$ Cidoncha Martín, A. (2006). La libertad de empresa (Derechos fundamentales y libertades públicas). Thomson Civitas. p.175.

${ }^{6}$ Ibidem. Cidoncha Martín, A. (2006). p.175-176

${ }^{7}$ Sobre la consideración de los derechos y libertades del Capítulo II del Título I de la CE como únicos derechos fundamentales véase, por ejemplo: Cruz Villalon, P. (1989). "Formación y evolución de los derechos fundamentales”. Revista española de Derecho constitucional, 25. p.39. También en la doctrina del Tribunal Constitucional, por ejemplo: España. Tribunal Constitucional. Sentencia núm. 247/2007 de 12 de diciembre, FJ 13.
} 
educación y el derecho a la salud son derechos sociales, debido a su ubicación dentro del texto, uno tiene la consideración de derecho fundamental y el otro no.

No faltan voces en contra de la anterior postura, que se asientan en bases tales como una interpretación alternativa a la mayoritaria sobre el artículo 53.3 de la $\mathrm{CE}^{8}$ o la íntima relación entre algunos artículos de los Capítulos II y III, como ocurre con el derecho a la vida y el derecho a la protección de la salud ${ }^{9}$.

En cualquier caso, este debate no nos puede hacer perder de vista el hecho de que el artículo 10.2 de la CE dicta que "las normas relativas a los derechos fundamentales y a las libertades que la Constitución reconoce se interpretarán de conformidad con la Declaración Universal de Derechos Humanos -en adelante DUDH- y los tratados y acuerdos internacionales sobre las mismas materias ratificados", habiéndose recogido en el artículo 25 de la DUDH "el derecho de toda persona a un nivel de vida adecuado que le asegure salud (...) y en especial la asistencia médica" y en el artículo 12 del Pacto Internacional de los Derechos Económicos Sociales y Culturales ${ }^{10}$ el derecho de toda persona a disfrutar del más alto nivel posible de salud física y mental. Eso solo en el contexto del Derecho Internacional de los Derechos Humanos, pues a nivel regional, dentro del marco del Consejo de Europa se han ratificado la Carta Social Europea -en adelante CSE- y el Convenio Europeo para la Protección de los Derechos Humanos y de las Libertades Fundamentales -en adelante CEDH- y dentro de la Unión Europea tras la ratificación del Tratado de Lisboa la Carta de los Derechos Fundamentales de la Unión Europea -CDFUE- tiene fuerza vinculante. La CSE y la CDFUE contienen referencias expresas al derecho a la salud, en concreto la CSE en la Parte I puntos 11 y 13 y en la Parte II artículo 11 y la CDFUE en el artículo 35. La CEDH no contiene referencias expresas al derecho a la protección de la salud, pero el Tribunal Europeo de los Derechos Humanos -en adelante TEDH- ha realizado una amplia labor de protección ${ }^{11}$ de éste a través de derechos íntimamente relacionados con el mismo y recogidos en el Convenio como el derecho a la vida -art.2 CEDH-.

Con este anclaje internacional y la cláusula contenida en el artículo 10.2 CE, podría haber parecido que pese al referido debate respecto a la ubicación el estatus del derecho a la

\footnotetext{
${ }^{8}$ Escobar Roca, G. (2017). El Derecho, entre el poder y la justicia: Una introducción crítica al sistema jurídico español. Tirant lo Blanch. pp.362-367.

${ }_{9}^{9}$ Mucho más limitada que la postura anterior, pues no concedería estatus al Título per se sino a determinados artículos del Título por su relación con otros considerados pacíficamente como fundamentales. Por ejemplo: León Alonso, M. (2009). La protección Constitucional de la Salud. La Ley. pp.149-150.

${ }_{10}$ Instrumento de Ratificación de España del Pacto Internacional de Derechos Económicos, Sociales y Culturales, hecho en Nueva York el 19 de diciembre de 1966. Boletín Oficial del Estado, 30 de abril de 1977, núm. 103.

${ }^{11}$ Tribunal Europeo de los Derechos Humanos. (2015). Thematic report: Health-related issues in the caselaw of the European Court of Human Rights. Consejo de Europa.
} 
protección de la salud estaba fuera de toda duda. Es más, desde la promulgación de la CE en 1978 hasta el año 2012, el derecho a la protección de la salud se fue perfilando y expandiendo progresivamente. Un hecho muy relevante en este sentido es la evolución que sufrió la configuración de la asistencia sanitaria, pasando progresivamente de un heredado sistema Bismarck ${ }^{12}$, que basa la titularidad del derecho en la aportación al sistema, a un sistema Beveridge ${ }^{13}$, que se asienta en el acceso universal a una sanidad financiada con cargo a impuestos ${ }^{14}$.

Sin embargo, en el año 2012, se aprueba el Real Decreto-ley 16/2012, de 20 de abril, de medidas urgentes para garantizar la sostenibilidad del Sistema Nacional de Salud y mejorar la calidad y seguridad de sus prestaciones, y los cimientos de este pensamiento vuelven a tambalearse $\mathrm{e}^{15}$. Con éste se produce un intento de retroceder al sistema Bismarck, donde prestaciones ${ }^{16}$ y personas ${ }^{17}$ previamente cubiertas de manera gratuita

${ }^{12}$ Sharma, M., Atri, A. (2011). “Essentials of international health”. Jones \& Bartlett Publishers. pp. 391 y ss.

${ }^{13}$ Ibidem.

Sharma, M., Atri, A. (2011). “Essentials of international health”. Jones \& Bartlett Publishers. pp. 391 y ss.

${ }^{14}$ Segovia de Arana, J. M. (2000). “Asistencia sanitaria y Seguridad Social en España”. Papeles y memorias de la Real Academia de Ciencias Morales y Políticas. pp.14-25.

${ }^{15}$ Lema Añón, C. (2014). "La titularidad del derecho a la salud en España: ¿hacia un cambio de modelo?’. Revista de Bioética y Derecho. pp. 3-16

16 A título meramente ejemplificativo: El artículo 4.5 del Real Decreto-Ley 16/2012 introdujo una modificación en el artículo 89.2 de la Ley 29/2006, de 26 de julio, de garantías y uso racional de los medicamentos y productos sanitario que otorga al Ministerio de Salud, Servicios Sociales e Igualdad -Poder Ejecutivo- el poder de revisar "los grupos, subgrupos, categorías y/o clases de medicamentos cuya financiación no se estime necesaria para cubrir las necesidades sanitarias básicas de la población española". Además, este mismo artículo excluyó "la prestación farmacéutica medicamentos sin receta, medicamentos que no se utilicen para el tratamiento de una patología claramente determinada, los productos de utilización cosmética, dietéticos, aguas minerales, elixires, dentífricos y otros productos similares (...) los medicamentos indicados en el tratamiento de síndromes y/o síntomas de gravedad menor, y aquellos que, aun habiendo sido autorizados de acuerdo a la normativa vigente en su momento, no respondan a las necesidades terapéuticas actuales, entendiendo por tal un balance beneficio/riesgo desfavorable en las enfermedades para las que estén indicados". Este mismo Real Decreto-Ley 16/2012 introdujo un artículo 85 ter en la misma ley - Ley 29/2006- que permitió al Ministerio de Salud, Servicios Sociales e Igualdad "Actualizar (...) la lista de medicamentos que están excluidos de los beneficios farmacéuticos en el Sistema Nacional de Salud", dando como resultado la Resolución de 2 de agosto de 2012, de la Dirección General de Cartera Básica de Servicios del Sistema Nacional de Salud y Farmacia, por la que se procede a la actualización de la lista de medicamentos que quedan excluidos de la prestación farmacéutica en el Sistema Nacional de Salud, que excluyó decenas de productos de la cartera. Asimismo, los artículos 4.12 y 4.13 del Real Decreto-Ley 16/2012 establecieron un sistema de aportaciones económicas en la prestación farmacéutica de los pensionistas.

${ }^{17}$ El artículo 1.1 del Real Decreto-Ley 16/2012 modificó sustancialmente el sistema de protección de la salud del que disfrutaban los inmigrantes excluyendo a aquellos que no dispusiesen de autorización de residencia del derecho a una asistencia sanitaria normalizada que tenían reconocido en virtud del art. 12 de la Ley Orgánica 4/2000, de 11 de enero, sobre derechos y libertades de los extranjeros en España y su integración social. Tras la reforma solo se prestaría asistencia sanitaria financiada con cargo a fondos públicos en casos de urgencia, embarazo y menores de edad. De manera añadida, este mismo artículo pretendió someter la asistencia sanitaria gratuita de las personas de nacionalidad española o de algún Estado miembro de la Unión Europea, del Espacio Económico Europeo o de Suiza que residan en España y los 
pasan a ser excluidas, hecho calificado por muchos como "medida regresiva en materia de derechos sociales" ${ }^{18}$ y como tal muy discutida por parte de la doctrina ${ }^{19}$. Sin embargo, pese a las críticas $^{20}$, las "rebeliones" 21 y las esperanzas traídas por el Auto del TC 239/2012, el TC en su Sentencia 139/2016 avalaría la constitucionalidad de prácticamente todo el citado Real Decreto-Ley con afirmaciones tan categóricas como las siguientes: "(el derecho a la protección de la salud) se trata de un derecho de configuración legal"; "la universalización del acceso a las prestaciones sanitarias sufragadas con fondos públicos, ha sido, desde la Ley 14/1986, de 25 de abril, general de sanidad (LGS), un objetivo a perseguir en el que no se ha llegado ni a la desvinculación absoluta con respecto a la Seguridad Social ni a un acceso incondicionado y gratuito para todos los residentes en territorio español"; "el reconocimiento del derecho (siempre ha precisado) de un título jurídico"; "es posible, en términos constitucionales, la falta de identidad entre el derecho al acceso universal al sistema de salud pública de ese "todos" del art. $43 \mathrm{CE}$, con que ese acceso a la sanidad pública incluya beneficiarse de un concreto régimen de prestaciones sanitarias gratuitas o bonificadas con cargo a fondos públicos" y "(aunque) supone un giro en la anterior política de progresiva extensión de la asistencia sanitaria gratuita o bonificada (...) la pretensión de universalidad acogida por el art. 43 CE se ha articulado de acuerdo con las previsiones legales existentes en cada momento, sin que hasta el momento haya significado el derecho incondicionado de toda persona residente o transeúnte que se halle en España a obtener gratuitamente todo tipo de prestaciones sanitarias". Es decir, entiende que pertenece al legislador decidir si a la vista de las circunstancias concurrentes -entre ellas las económicas ${ }^{22}$ la asistencia sanitaria debe prestarse de manera gratuita.

Quedan para consuelo el fallo sobre el art. 3.3 de la Ley 16/2003 Sistema Nacional de Salud, en la redacción dada por el art. 1.1 del Real Decreto-ley 16/2012, cuyo objetivo era ampliar el colectivo de asegurados a personas que, en principio, no tenían vínculo con el sistema de seguridad social (personas de nacionalidad española o de algún otro estado de la UE, del Espacio Económico Europeo o de Suiza, y a los extranjeros titulares de una

extranjeros titulares de una autorización para residir en territorio español a un límite de ingresos determinado reglamentariamente -este último inciso fue declarado inconstitucional por la STC 139/2016, que comentamos a continuación, por deslegalización de la reserva de ley del artículo 43 CE-.

${ }^{18}$ Por todos: Delgado del Rincón, L. (2019). El derecho a la asistencia sanitaria de los extranjeros: limitaciones y problemas competenciales. Tirant lo Blanch. pp.43-45.

${ }^{19}$ Ibidem. Delgado Rincón, L. (2019). pp. 44-45.

${ }^{20}$ Entre otros: Defensor del Pueblo. (2012). Informe Anual: Anexo E.5. Solicitudes de intervención ante el tribunal constitucional. pp.42-56 // Defensor del Pueblo. (2015). Informe: Las urgencias hospitalarias en el sistema nacional de salud: derechos y garantías de los pacientes. estudio conjunto de los defensores del pueblo.

${ }^{21}$ Recordemos que las CCAA intentaron minimizar los impactos de este RD-L con distintos instrumentos. Por todos: Arrese Iriondo, M. N. (2016). "Competencia de las Comunidades Autónomas en materia de sanidad y asistencia sanitaria a las personas migrantes en situación irregular". Revista Aragonesa de Administración Pública. pp. 215-222

${ }^{22}$ Ibidem. Escobar Roca, G. (2017). pp.362-367. 
autorización para residir en territorio español) pero supeditando esto a que acreditasen que no superaban un límite de ingresos "determinado reglamentariamente". Según el TC la literalidad del citado inciso "impide determinar quiénes van a tener dicha condición, dejando la decisión exclusivamente en manos del Gobierno (lo que) contiene una patente deslegalización que sacrifica la reserva de ley ex artículo 43.2 CE". Por lo tanto, declara el inciso inconstitucional y nulo.

También quedan los votos particulares hechos en la misma, donde no solo se incide en el carácter del derecho a la protección de la salud a la vista de los compromisos internacionales asumidos, sino también en la presencia de deficiencias en la realización del test de proporcionalidad agravado que debía pasar esta medida como regresiva en materia de los derechos sociales. En concreto apunta el Magistrado Valdés Dal-Ré que "la exclusión declarada, no es proporcional al fin que se dice perseguido, que remite a la sostenibilidad financiera del sistema público sanitario (...) porque a la medida le falta la mínima coherencia con la finalidad pretendida, o al menos declarada, que es garantizar la sostenibilidad del sistema, al no haber tenido en cuenta la capacidad económica de aquellos a quienes se excluye. Quien carece de medios económicos para subvenir a sus necesidades sanitarias ni va a pagar la asistencia en el servicio público, ni va a derivar a un servicio privado, terminando en numerosas ocasiones por hacer uso del servicio público de urgencias, que sí está previsto independientemente de la situación económica y de la condición administrativa del usuario".

En el año 2018, que el Real Decreto-ley 7/2018, de 27 de julio, sobre el acceso universal al Sistema Nacional de Salud, pretendió revertir la situación provocada por el Real Decreto 16/2012 reconociendo el derecho a la asistencia sanitaria gratuita a todos aquellos que no dispusieran de otro obligado a hacer frente al pago de esta. No obstante, este objetivo se ha visto desvirtuado por la ambigüedad que presenta su redacción. Tan solo cuatro meses después de su entrada en vigor, REDER, la red de resistencia y denuncia al Real Decreto-Ley 16/2012, ya denunciaba cinco problemas fundamentales aparejados al Real Decreto-ley 7/2018 23 : la falta de armonización en los requisitos para obtener asistencia sanitaria con cargo a fondos públicos en las diferentes Comunidades Autónomas -en adelante CCAA-; la exigencia en la mayoría de las CCAA de una antigüedad mínima de tres meses en el padrón para poder acceder al sistema sanitario público, existiendo lugares dónde se requiere que la persona se encuentre en una situación administrativa regular para poder empadronarla; la ausencia de un precepto que garantice en todo caso la asistencia sanitaria gratuita de los colectivos más vulnerables: embarazadas, menores de 18 años, víctimas de trata, solicitantes de asilo y personas que

${ }^{23}$ REDER. (2018). Es urgente garantizar la sanidad universal. No dejar nadie atrás. Recuperado de: https://drive.google.com/file/d/1llLcsc7gn9xL4Djcjto9u7O2xccQ9SNd/view 
requieran atención en $\operatorname{urgencias}^{24}$; y la deficiente solución aportada para aquellas personas ascendientes reagrupadas a las que no se concede la tarjeta sanitaria pero tampoco pueden acceder a un seguro de salud privado por su edad y condiciones de salud preexistentes. Debido a estos problemas y a espera del desarrollo reglamentario del citado Real Decreto-Ley, REDER entendía la tramitación de este como proyecto de ley ${ }^{25}$ como una oportunidad para mejorar la norma ${ }^{26}$. Sin embargo, esto nunca llegó a suceder pues las Cortes Generales se disolvieron ante una convocatoria anticipada de elecciones generales $^{27}$. Por lo tanto, actualmente, el Real Decreto-Ley 7/2018 sigue vigente con su redacción original y los problemas aparejados a esta ${ }^{28}$.

Es cierto, que hubo un pequeño lapso temporal en el que España tenía un sistema bastante cercano a lo que podríamos considerar asistencia sanitaria universal gratuita ${ }^{29}$, pero no es menos cierto que esta no es la situación actual y que pese a la lucha constante de la

\footnotetext{
${ }^{24}$ En el citado informe de REDER, red creada para la defensa y resistencia ante el Real Decreto-ley 16/2012, llega a decir lo siguiente "La normativa de 2012, contemplaba el derecho a la asistencia de forma incondicional en cinco supuestos: mujeres embarazadas, menores de 18 años, víctimas de trata, solicitantes de asilo y la atención de urgencia hasta el alta médica. Incluso una norma tan regresiva de derechos como era aquella entendía que la particular situación de vulnerabilidad de estas personas requería garantizar la asistencia con cargo a fondos públicos. El nuevo RDL 7/2018, desde su vocación de universalidad, reconoce el derecho a la protección de la salud a todas las personas extranjeras no registradas ni autorizadas a residir en España, sin singularizar las mencionadas situaciones especiales. Sin embargo, este reconocimiento general queda supeditado al cumplimiento de una serie de requisitos referidos a demostrar que la persona no tiene cobertura sanitaria por otra vía. Independientemente de la mayor o menor dificultad que cada persona pueda tener para aportar prueba de estos requisitos, que la ley no especifique las garantías de que estas cinco situaciones serán atendidas por el sistema público de salud significa ignorar la especial vulnerabilidad y puede dar lugar a una regresión del derecho a la salud."

${ }^{25}$ Congreso de los Diputados. (2018). Diario de Sesiones del Congreso de los Diputados Pleno y Diputación Permanente. XII Legislatura Núm. 144. Sesión plenaria núm. 137 celebrada el jueves, 6 de septiembre de 2018 Recuperado de: http://www.congreso.es/portal/page/portal/Congreso/PopUpCGI?CMD=VERLST\&BASE=pu12\&DOCS $=1$-1\&QUERY=\%28DSCD-12-PL-144.CODI.\%29\#(P\%C3\%A1gina34)

${ }^{26}$ Amnistía Internacional. (2018). España: Cuatro meses después del nuevo decreto sobre sanidad universal se deben abordar sus fallos y ambigüedades. Recuperado de: https://www.es.amnesty.org/enque-estamos/noticias/noticia/articulo/espana-cuatro-meses-despues-del-nuevo-decreto-sobre-sanidaduniversal-se-deben-abordar-sus-fallos-y/

${ }^{27}$ Congreso de los Diputados. (2018). Proyecto de Ley 121/000024 sobre el acceso universal al Sistema Nacional de Salud (procedente del Real Decreto-ley 7/2018, de 27 de julio). Recuperado de: http://www.congreso.es/portal/page/portal/Congreso/Congreso/Iniciativas?_piref73 $2148295 \quad 73 \quad 133543$ 7_1335437.next_page=/wc/servidorCGI\&CMD=VERLST\&BASE=IW12\&PIECE=IWA2\&FMT =INITX D1S.fmt\&FORM1 $=$ INITXLUS.fmt\&QUERY $=\% 281 \% 29$. ACIN1.+\%26+\%28REAL+DECRETOLEY+7\%2F2018\%29.ALL.\&DOCS=1-1

${ }^{28}$ REDER. (2019). Organizaciones sociales exigen una nueva regulación que recupere el derecho a la salud de todas las personas. Recuperado de: https://reder162012.org/index.php?option=com _k2\&view=item\&id=314:organizaciones-sociales-exigenuna-nueva-regulacion-que-recupere-el-derecho-a-la-salud-de-todas-las-personas\&Itemid=762

${ }^{29}$ Véase Fundamento Jurídico 8 de la Sentencia del Tribunal Constitucional 139/2016, de 21 de julio de 2016.
} 
doctrina ${ }^{30}$ y la sociedad civil ${ }^{31}$, la cuestión a corto plazo se torna complicada pues la nueva regulación es muy ambigua y el TC ya avaló casi en su totalidad el regresivo Real Decreto-Ley $16 / 2012^{32}$.

Partiendo de la base de que es imperativo urgir a los poderes públicos a que cuanto menos se alineen con los compromisos internacionales asumidos en materia de derecho a la salud $^{33}$, lo cierto es que actualmente es posible que una persona vea rechazada su petición de obtener asistencia sanitaria gratuita ${ }^{34}$, sienta incertidumbre sobre la cobertura en caso de tener una enfermedad ${ }^{35}$ o dude sobre el panorama futuro en caso de que las medidas regresivas se sigan sucediendo. Estos riesgos llevan a las personas al deseo de tratar de eliminar o reducir estas posibilidades, habiéndose demostrado el seguro como una de las técnicas más refinadas y efectivas en la previsión y cobertura de daños ${ }^{36}$. En este caso, el seguro apropiado para cubrir este riesgo sería el seguro de asistencia sanitaria privada, que como bien apunta el Informe Anual del Defensor del Pueblo en 2011, tiene el objetivo de "complementar la asistencia pública de salud y permitir el derecho a la protección de la salud al que alude el artículo 43 de la Constitución". No obstante, como veremos a continuación, no todas las personas pueden contratar este producto.

\footnotetext{
${ }^{30}$ Lema Añón, C. (2018). "El derecho a la salud ante sus cuatro flagelos: mercantilización, recortes, exclusión y desigualdad. Por una ciudadanía de la salud democrática y en igualdad". pp. 609-613. En VV.AA. Lucas, J., Rodríguez Uribes, J. Derechos Humanos y Constitución. Tirant lo Blanch.

${ }^{31}$ Entre otros ejemplos: Íbidem. REDER. (2019).

${ }^{32}$ Ibidem. Lema Añón, C. (2018). pp. 601-609.

${ }^{33}$ Ibidem. Lema Añón, C. (2018). pp. 609 y ss.

${ }^{34}$ REDER. (2018). Es urgente garantizar la sanidad universal. No dejar nadie atrás. Pág.12: Las cifras de la exclusión. Recuperado de:https://drive.google.com/file/d/1llLcsc7gn9xL4Djcjto9u7O2xccQ9SNd/view ${ }^{35}$ Entre otros: Defensor del Pueblo. (2018). Informe Anual. Defensor del Pueblo. Pág.409 - 410 "El Defensor del Pueblo viene recibiendo diversas quejas que reflejan la preocupación de los profesionales sanitarios por las condiciones en que desarrollan su trabajo, como consecuencia de la problemas referidos a una infradotación presupuestaria de los servicios de salud, muy especialmente en el nivel de la atención primaria, con particular incidencia en una dotación de recursos humanos insuficiente y en condiciones de precariedad laboral, además de otras cuestiones de carácter estructural y organizativo. Se trata de circunstancias arrastradas desde hace varios años, para las que las administraciones públicas no estarían ofreciendo la debida respuesta, a pesar de estar bien identificadas, cronificándose algunos problemas que hacen temer por un deterioro de la atención sanitaria pública"' con carácter general, el Defensor del Pueblo considera que los datos que muestran importantes carencias en el nivel de atención primaria del sistema público de salud, en forma de precarización y falta de medios, exigen una reacción efectiva de todos los poderes públicos, que pudiera concretarse en un acuerdo de ámbito estatal para la garantía de la suficiencia del sistema, adaptada a las diferencias territoriales y las distintas necesidades en cada comunidad autónoma".

${ }^{36}$ VV.AA. Jiménez Sánchez, G., Díaz Moreno, A. (2013). Derecho mercantil. Vol. 9, Los contratos de seguro. Marcial Pons. pp. 2-5
} 


\section{Seguros de asistencia sanitaria y discapacidad}

\subsection{Una cuestión que sobrepasa nuestras fronteras}

No es un secreto que las personas con discapacidad encuentran barreras en el acceso y la permanencia en los contratos de seguro de asistencia sanitaria. Un hito claro en la prueba de esta situación la encontramos en la contribución de Benjamin Schatz a la Revista de Derecho de la Universidad de Harvard en el año 1987 denominada "The AIDS insurance crisis: Underwriting or overreaching?" -La crisis de los seguros a causa del SIDA: ¿limitación o extralimitación en el producto ${ }^{37}$-. En ésta se habla de cómo las compañías de seguros estaban tratando de aminorar los costes asociados al descubrimiento del SIDA $^{38}$ mediante prácticas como el encuadramiento de los tratamientos para el VIH dentro de la categoría "tratamientos experimentales", no cubiertos por la mayoría de las compañías aseguradoras, o la denegación de cobertura en aquellos casos en los que el asegurado hubiese mostrado signos de la presencia del VIH aun cuando no fuese consciente de la infección. Al hilo de esta contribución, en los años siguientes, se sucedieron numerosas contribuciones en el campo de la Economía y el Derecho que no solo permitirían desgranar los costes asociados al VIH que las aseguradoras habían enfrentado $^{39}$, sino también constatar que las situaciones denunciadas por Schatz se repetían incluso en aquellos países donde el derecho a la salud parecía estar garantizado por el Estado ${ }^{40}$.

El origen de estas situaciones se encuentra en la esencia de la técnica aseguradora. Es decir, los seguros se asientan sobre unos elementos técnicos, los cuales permiten entre otras cosas adoptar medidas conducentes a aceptar aquellos riesgos que ofrezcan una

\footnotetext{
${ }^{37}$ Se ha intentado aportar una traducción del título que reflejase el sentido del título original, pues una traducción más literal podría tener connotaciones no probadas como pretendidas en el cuerpo del artículo cuyo título se traduce.

${ }^{38}$ En este artículo se sigue la (no)definición de persona con discapacidad sustentada por el artículo 1 de la Convención sobre los Derechos de las Personas que entiende incluidas a todas aquellas personas que "tengan deficiencias físicas, mentales, intelectuales o sensoriales a largo plazo que, al interactuar con diversas barreras, puedan impedir su participación plena y efectiva en la sociedad, en igualdad de condiciones con las demás". Dentro de esta definición se encuadran las personas con VIH y así consta en: ONUSIDA, OMS, UNHR. (2009). Disability and HIV policy brief. p.1. En concreto se dice que, aunque la Convención sobre los Derechos de las Personas con Discapacidad no menciona de manera explícita al VIH en su definición de discapacidad, los Estados que la adopten deberán reconocer que cuando las personas que tienen VIH (incluso si son asintomáticas) tienen impedimentos que en interacción con el entorno resultan en estigma, discriminación u otras barreras para participar en la sociedad, pueden ser incluidas dentro de la protección brindada por la Convención.

${ }^{39}$ Christianson, D., Beal, R., Deutscher, H., Gill, A., Koenig, W., Reese, T., Samoff, P. (1990). "The financial implications of aids for life insurance companies in the united states". Transactions of Society of Actuaries vol. 42. // VV.AA. Holland, D. (1988). "The impact of aids on life and health insurance companies: a guide for practicing actuaries". Transactions of Society of Actuaries vol. 40. p. 2. // Strable, D. (1990). The financial impact of aids on life insurance. Master Thesis. NorthWestern University. // De Voy, K. (1988). The effects of aids on the insurance industry. Tesis. Ball State University, Muncie, Indiana. ${ }^{40}$ Fagnart, J. (1991). Les assurances et le sida: Le SIDA, un defi aux droits. Bruylant // Fagnart, J. (1996). SIDA, assurances er vie privee. Reveu belge du dommage corporel. p.43.
} 
menor peligrosidad y rechazar aquellos que puedan ocasionar desequilibrios -selección de riesgos- ${ }^{41}$. Sobre esta selección se ha llegado a afirmar lo siguiente: "El proceso de Selección de Riesgo debe realizarse de forma rigurosa para evitar la entrada en la Compañía de asegurados con afecciones que impliquen riesgos. Estas afecciones debido al mayor riesgo que supone para la entidad implican un aumento de la siniestralidad y disminuyen los beneficios de la Compañía. (...) La situación ideal sería la de un número elevado de nuevos asegurados sin patologías previas". En principio, la diferenciación basada en estereotipos o en prejuicios sin aportar justificación es discriminatoria y por lo tanto debe ser prohibida. Pero ¿qué sucede con la diferenciación basada en hallazgos actuariales? ¿es discriminatoria o simplemente moralmente cuestionable?

En el año 2000, se fijarían en el seno de la Organización de Naciones Unidas -en adelante ONU- los Objetivos de Desarrollo del Milenio -en adelante ODM-. Estos aluden en tres de sus ocho objetivos a la salud, a saber: reducir la mortalidad infantil $\left(4^{\circ}\right)$, mejorar la salud materna $\left(5^{\circ}\right)$ y combatir el VIH/SIDA, el paludismo y otras enfermedades $\left(6^{\circ}\right)$. A simple vista, la conexión de estos con los seguros de asistencia sanitaria parece compleja, pero nada más lejos de la realidad, pues la financiación sostenible de los sistemas de salud es esencial para garantizarlos. Así lo reconocería la OMS en 2003 en su "Informe sobre la Salud en el Mundo 2003"42 con las siguientes palabras "para sostener el sistema de salud sin depender estrechamente de los honorarios es necesario movilizar otras fuentes, incluidos (...) primas de seguros privados”. Extremo que ratificaría el Informe preparado en 2015 por la ONU sobre los ODM cuando a colación de los avances producidos en la consecución de la meta 6.C -haber detenido y comenzado a revertir la incidencia del paludismo y otras enfermedades graves- dice “(...) una financiación previsible e inversiones estratégicas en sistemas de salud, control de enfermedades y nuevas herramientas son necesarios para reducir el resurgimiento y los brotes del paludismo en los próximos años" ${ }^{\text {43 }}$. No obstante, la relación entre estos seguros y el derecho a la salud quedaría fijada de manera mucho más clara en otro documento, la Observación General No 14 del Comité de derechos económicos, sociales y culturales de la ONU ${ }^{44}$ que remarcaría que "los pagos por servicios de atención de la salud y servicios relacionados con los factores determinantes básicos de la salud deberán basarse en el principio de la

\footnotetext{
${ }^{41}$ Herrera Ruiz, F.J. (2009). Selección de riesgo en el seguro de salud. Tesis del Máster en Dirección de Entidades Aseguradoras y Financieras. Universidad de Barcelona. Literalmente: "El proceso de Selección de Riesgo debe realizarse de forma rigurosa para evitar la entrada en la Compañía de asegurados con afecciones que impliquen riesgos. Estas afecciones debido al mayor riesgo que supone para la entidad implican un aumento de la siniestralidad y disminuyen los beneficios de la Compañía." "La situación ideal sería la de un número elevado de nuevos asegurados sin patologías previas."

42 OMS. (2003). Informe sobre la Salud en el Mundo 2003. p.135. Recuperado de: https://apps.who.int/iris/handle/10665/42822

43 ONU. (2015). Objetivos de Desarrollo del Milenio. Informe 2015. Recuperado de: https://www.undp.org/content/undp/es/home/librarypage/mdg/the-millennium-development-goals-report2015.html

${ }^{44}$ ONU. (2000). E/C.12/2000/4, CESCR Observación General 14.
} 
equidad, a fin de asegurar que esos servicios, sean públicos o privados, estén al alcance de todos, incluidos los grupos socialmente desfavorecidos" ${ }^{\text {"2 }}$. Es más, esta observación va un paso más adelante y no solo establece esta relación, sino que aborda la cuestión aquí planteada subrayando la necesidad de que "no sólo el sector de la salud pública, sino también los establecimientos privados que proporcionan servicios de salud cumplan el principio de no discriminación en el caso de las personas con discapacidades" ${ }^{\text {46 }}$.

En línea con esta Observación General, la Convención sobre los Derechos de las Personas con Discapacidad -en adelante CDPD- aprobada en 2006 prevé en su artículo 25 e) la prohibición expresa de discriminar a las personas con discapacidad en la prestación de seguros de salud y vida e insta a los Estados Parte a velar por que estos se presten de manera justa y razonable ${ }^{47}$. Previsión sobre la que incidirían en 2009 la Organización Mundial de la Salud -en adelante OMS-, ONUSIDA y la Oficina del Alto Comisionado para los Derechos Humanos de Naciones Unidas en un informe conjunto sobre políticas relativas al VIH y la discapacidad ${ }^{48}$. En este documento, no solo se afirmaría que cuando las personas que viven con el VIH (incluso si son asintomáticas) tienen impedimentos que en interacción con el entorno resultan en estigma, discriminación u otras barreras para participar en la sociedad deben ser incluidas dentro de esta definición, sino que también se asevera que "la CDPD requiere que los Estados Partes prohíban todas las formas de discriminación en contra de las personas con discapacidad que puedan impedir el acceso (en entre otros) a los seguros de salud y vida" ${ }^{\prime 4}$.

Con esta Convención ocurrió en nuestro ámbito regional una circunstancia insólita, pues se convertiría en el primer tratado exhaustivo sobre derechos humanos ratificado por el conjunto de la Unión Europea -en adelante UE- ${ }^{50}$. No obstante, para el momento en el que se produce la ratificación, el debate sobre esta cuestión ya se había servido en la UE, primero, con la Directiva del Consejo 2004/113/CE de 13 de diciembre de 2004 por la que se aplica el principio de igualdad de trato entre hombres y mujeres al acceso a bienes y servicios y su suministro -en adelante DITHM- y más tarde, con la Propuesta de Directiva del Consejo por la que se aplica el principio de igualdad de trato entre las personas independientemente de su religión o convicciones, discapacidad, edad u orientación sexual -en adelante PDITRCDEO-.

\footnotetext{
45 ONU. (2000). E/C.12/2000/4, CESCR Observación General 14. Punto 12

${ }^{46}$ ONU. (2000). E/C.12/2000/4, CESCR Observación General 14. Punto 26

${ }^{47}$ España ratificó la Convención y su Protocolo Facultativo el 21 de abril de 2008, y entró en vigor el 3 de mayo de ese mismo año.

48 ONUSIDA, OMS, UNHR. (2009). Disability and HIV policy brief. Recuperado de: http://www.who.int/disabilities/jc1632_policy_brief_disability_en.pdf

49 Íbidem. ONUSIDA, OMS, UNHR. (2009).

${ }^{50}$ Unión Europea. (2009). Decisión del Consejo 2010/48/CE de 26 de noviembre de 2009 relativa a la celebración, por parte de la Comunidad Europea, de la Convención de las Naciones Unidas sobre los derechos de las personas con discapacidad. Diario Oficial de la Unión Europea, L 23/35.
} 
Respecto a la primera Directiva, cabe destacar que durante el proceso conducente a su aprobación se produjo una contienda entre las compañías aseguradoras y la Comisión. Por una parte, las aseguradoras se oponían a que el uso del sexo en el cálculo de las primas de seguros fuese considerado discriminatorio pues alegaban que sin el uso de este factor el mercado se distorsionaría y no serían capaces de asumir las responsabilidades contraídas. Por otra parte, la Comisión defendía que no solo existían países en la UE que no usaban el sexo para la confección de las primas, sino que se había demostrado que había mejores parámetros para determinar el riesgo ${ }^{51}$. Con todo ello, el texto aprobado reflejaba un medio camino entre ambas posturas, pues si bien el artículo 5.1 DITHM preámbulo 18- establece que "los Estados miembros velarán por que en todos los nuevos contratos que se celebren (...) el hecho de tener en cuenta el sexo como factor de cálculo de primas y prestaciones a efectos de seguros (...) no dé lugar a diferencias en las primas y prestaciones de las personas consideradas individualmente", el artículo 5.2 DITHM preámbulo 19- permitiría que los Estados miembros pudieran decidir "autorizar diferencias proporcionadas de las primas y prestaciones de las personas consideradas individualmente en los casos en que la consideración del sexo constituya un factor determinante de la evaluación del riesgo a partir de datos actuariales y estadísticos pertinentes y exactos". Sin embargo, esta solución no duraría mucho, pues en marzo de 2011 el Tribunal de Justicia de la UE -en adelante TJUE- fallaría que el artículo 5.2 DITHM era invalido ${ }^{52}$. Tal fue el impacto del fallo que la Comisión publicó en diciembre de ese mismo año unas "Directrices sobre la aplicación de la Directiva 2004/113/CE del Consejo a los seguros, a la luz de la sentencia del Tribunal de Justicia de la Unión Europea en el asunto C-236/09 (Test-Achats)"53. En 2015 el "Informe de la Comisión al Parlamento Europeo, al Consejo y al Comité Económico y Social Europeo sobre la aplicación de la Directiva 2004/113/CE del Consejo, por la que se aplica el principio de igualdad de trato entre hombres y mujeres al acceso a bienes y servicios y su suministro",54 analizaría de nuevo las repercusiones del fallo y su conclusión no dejaría lugar a dudas "el impacto de la introducción del principio de tarificación unisex de los seguros parece haber sido, en general, insignificante o moderado".

Respecto a la segunda, la PDITRCDEO, cabe destacar que cuando se inició el proceso para su confección, el caso Test-Achats no había sido resuelto, pero ello no obsta en la

\footnotetext{
${ }^{51}$ Unión Europea. (2003). Propuesta de Directiva del Consejo por la que se aplica el principio de igualdad de trato entre mujeres y hombres al acceso a bienes y servicios y su suministro \{SEC (2003) 1213\}.

52 Tribunal de Justicia de la Unión Europea. Sentencia de 1 de marzo de 2011, Test-Achats, C-236/09, ECLI:EU:C:2011:100.

${ }^{53}$ Unión Europea. (2012). Directrices sobre la aplicación de la Directiva 2004/113/CE del Consejo a los seguros, a la luz de la sentencia del Tribunal de Justicia de la Unión Europea en el asunto C-236/09 (TestAchats), C 11/1.

${ }^{54}$ Unión Europea. (2015). Informe de la Comisión al Parlamento Europeo, al Consejo y al Comité Económico y Social Europeo: Informe sobre la aplicación de la Directiva 2004/113/CE del Consejo, por la que se aplica el principio de igualdad de trato entre hombres y mujeres al acceso a bienes y servicios y su suministro. COM (2015) 190 final
} 
apreciación de que las compañías aseguradoras tomaron una posición muy similar a la asumida en relación con la DITHM, según las mismas la aplicación de criterios de discapacidad en el sector asegurador no representa una discriminación en todos los productos $^{55}$. Sea como fuere, el artículo 2 de la PDITRCDEO dice que:

"en los servicios financieros, los Estados miembros podrán decidir autorizar diferencias de trato ajustadas en caso de que, para el producto en cuestión, la consideración de (...) la discapacidad constituya un factor determinante de la evaluación del riesgo a partir de datos actuariales y estadísticos pertinentes y exactos", pues según las explicaciones al artículo se entiende que "si las aseguradoras no pudieran tener en cuenta en absoluto (...) la discapacidad, los costes adicionales que de ello se derivarían correrían a cargo del resto de los asegurados, lo que redundaría en unos gastos generales mayores y en una menor disponibilidad de cobertura para los consumidores".

El Parlamento Europeo ya mostró su disconformidad con esta previsión ${ }^{56}$, considerando que de introducirse esta limitación la redacción debería ser más concreta. No obstante, pese a los compromisos de retomar el proceso para la aprobación de esta directiva ${ }^{57}$, lo cierto es que aún sigue siendo una propuesta, con los problemas que esto acarrea a la UE como signataria de la CDPD.

Con este contexto internacional de fondo, no es de extrañar que en 2015, en la Resolución de 25 de septiembre, de la Asamblea General de las Naciones Unidas por la que se aprueban los Objetivos de Desarrollo Sostenible -en adelante ODS-, este tema, que puede parecer a primera vista muy secundario, se incluyese en el programa. Los ODS no solo refieren literalmente en el punto 23 que "es necesario empoderar a las personas vulnerables (...) las personas con discapacidad (...), las personas que viven con el VIH/SIDA... " y en el punto 26 que "para promover la salud y el bienestar físicos y mentales y prolongar la esperanza de vida de todas las personas, debemos lograr que la cobertura sanitaria y el acceso a una atención médica de calidad sean universales, sin excluir a nadie", sino que en el Octavo Objetivo denominado "Promover el crecimiento económico sostenido, inclusivo y sostenible, el empleo pleno y productivo y el trabajo

\footnotetext{
${ }^{55}$ Unión Europea. (2008). Propuesta de Directiva del Consejo por la que se aplica el principio de igualdad de trato entre las personas independientemente de su religión o convicciones, discapacidad, edad u orientación sexual. "2. Consulta de las partes interesadas y evaluación de impacto". \{SEC(2008) 2180\} \{SEC(2008) 2181\}.

${ }^{56}$ Unión Europea. Resolución legislativa del Parlamento Europeo, de 2 de abril de 2009 sobre la Propuesta de Directiva del Consejo por la que se aplica el principio de igualdad de trato entre las personas independientemente de su religión o convicciones, discapacidad, edad u orientación sexual. (COM(2008)0426). Recuperado de: https://eur-lex.europa.eu/legalcontent/EN/TXT/?uri=celex\%3A52009AP0211

${ }^{57}$ Unión Europea. (2018) Outcome of the 3625th Council meeting Employment, Social Policy, Health and Consumer Affairs Employment, Social Policy and Health issues. Recuperado de: https://www.consilium.europa.eu/media/35974/st10202-en18.pdf
} 
decente para todos" dentro del punto 10 se aborda frontalmente la cuestión aquí debatida con la siguiente formulación: "fomentar y ampliar el acceso a los servicios bancarios, financieros y de seguros para todos".

\subsection{La preocupación por la materia: El rol del Defensor del Pueblo}

Muchos pueblos se han comprometido con la Agenda 2030, que pretende hacer realidad los derechos humanos de todas las personas ${ }^{58}$, pero esta es ambiciosa, compleja, en proceso de construcción permanente, ambigua y con importantes contradicciones ${ }^{59}$, lo que hace necesario contar con aquellos que sean competentes para analizar las cuestiones desde la perspectiva de los derechos humanos y con este análisis inspiren, promuevan y guíen la transformación de las políticas públicas. Sin embargo, esto nos hace plantearnos quienes son aquellos capaces. Pues bien, no cabe duda de que entre ellos estaría el Defensor del Pueblo, garante simultaneo de los derechos humanos y los derechos fundamentales ${ }^{60}$. Institución que en España fue dibujada en el artículo 54 CE para que tras la designación por las Cortes Generales fuese defensora de los derechos comprendidos en el Título I CE, y que tras el desarrollo en la Ley Orgánica 3/1981, de 6 de abril, del Defensor del Pueblo, se ha convertido en una institución a la que ciudadanos y colectivos ${ }^{61}$ pueden acudir de manera gratuita para defender sus derechos de manera informal -no requiere la asistencia de abogado y/o procurador-, lo que favorece la construcción de los derechos "desde abajo"62.

El trabajo de los defensores del pueblo en el ámbito del derecho a la protección de la salud derivado de las competencias públicas en la materia, al margen de que su posición pueda

\footnotetext{
${ }^{58}$ Organización de Naciones Unidas. (2015). Resolución A/RES/70/1 aprobada por la Asamblea General el 25 de septiembre de 2015.

${ }^{59}$ Gil Payno, M. (2018). "Experiencias y desafios de la agenda 2030 y los ODS: el índice de coherencia de políticas para el desarrollo”. p.132. En VV.AA. Escobar Roca, G. (2018). Las Defensorías del Pueblo iberoamericanas ante la Agenda 2030. PRADPI

${ }^{60}$ Escobar Roca, G. (2011). Derechos sociales y tutela antidiscriminatoria. Thomson-Aranzadi. p.733.

${ }^{61}$ Sobre la labor del Defensor del Pueblo y la defensa de las personas y grupos vulnerables véase: Fernández Miguelez, A. Rodríguez Cuenca, A. (2013). Las defensorías del pueblo y la defensa de las personas y grupos vulnerables. pp.373 y ss. En VV.AA. Presno Linera, M.A. (2013). Protección jurídica de las personas y los grupos vulnerables. Universidad de Oviedo, Procuradora General del Principado de Asturias.

62 Tomamos prestada esta expresión de la publicación de Escobar Roca, G. (2010). "Interpretación y garantía de los derechos fundamentales por el defensor del pueblo (Análisis empírico, reconstrucción dogmática y propuesta de futuro"). Teoría y Realidad Constitucional, 26. p.231, que a su vez parece haber tomado esta expresión del libro editado por VV.AA. De Sousa Santos, B. Rodríguez Garavito, C. (2007). El derecho y la globalización desde abajo. Anthropos, pero aplicándola a este contexto especifico.
} 
ser más ${ }^{63}$ o menos criticable ${ }^{64}$, es obvia e innegable ${ }^{65}$. A título meramente ejemplificativo podemos destacar las acciones llevadas a cabo a raíz del citado Real Decreto-ley $16 / 2012^{66}$, entre ellas la publicación del informe "Las urgencias hospitalarias en el sistema nacional de salud: derechos y garantías de los pacientes. Estudio conjunto de los defensores del pueblo"67 y la resolución de quejas relacionadas con el copago farmacéutico $^{68}$, la asistencia sanitaria a inmigrantes en situación irregular ${ }^{69}$, el acceso a la prestación sanitaria de la seguridad social a los ciudadanos españoles perceptores de prestaciones provenientes de suiza ${ }^{70}$ o la falta de asistencia sanitaria de familiares de

${ }^{63}$ Ibidem. Lema Añón, C. (2018). Pp. 606-607. En relación con la actuación del Defensor del Pueblo ante la petición de que la institución presentase un recurso de inconstitucionalidad al Real Decreto-Ley 16/2012 "El Defensor del Pueblo despacho las peticiones que planteara un recurso de inconstitucionalidad con unas consideraciones que lo mejor que le puede pasar al prestigio de la institución es que sean olvidadas".

${ }^{64}$ Sobre la interpretación del derecho a la protección de la salud por el Defensor del Pueblo véase: Celi Maldonado, A. (2018). La interpretación de los derechos sociales por el Defensor del pueblo. Tirant lo Blanch. pp.309-416.

${ }^{65}$ Sobre el rol de los defensores del pueblo en la protección a la salud véase: VV.AA. Escobar Roca, G. (2006). IV Informe sobre derechos humanos: protección de la salud. Federación Iberoamericana de Ombudsman. Recuperado de: https://pradpi.es/informes/informe_salud.pdf

${ }^{66}$ Estas actuaciones tampoco han escapado del análisis de la doctrina. Vid., por ejemplo: Centenera Sánchez-Seco, F. (2017). "Las acciones de las defensorías del pueblo sobre el acceso de los inmigrantes en situación irregular a la asistencia sanitaria: a propósito de los análisis sobre la racionalidad normativa". pp.109-124 y Delgado del Rincón, L. (2017). "El Defensor del Pueblo ante la desigual protección del derecho a la salud de los inmigrantes en situación irregular en el Estado Español”. (pp.185-212). En Escobar Roca, G,. (2017). Ombudsman y Colectivos en situación de vulnerabilidad. Tirant lo Blanch.

${ }^{67}$ Defensor del Pueblo de España. (2015). Informe: Las urgencias hospitalarias en el sistema nacional de salud: derechos y garantías de los pacientes. Estudio conjunto de los defensores del pueblo". Recuperado de: https://www.defensordelpueblo.es/informe-monografico/las-urgencias-hospitalarias-en-el-sistemanacional-de-salud-derechos-y-garantias-de-los-pacientes-estudio-conjunto-de-los-defensores-del-puebloenero-2015/ Literalmente: "Diversas asociaciones y organizaciones no gubernamentales han hecho llegar a los Defensores del Pueblo estudios de casos sobre las irregularidades que se están sucediendo en el acceso de los inmigrantes sin autorización de residencia a la asistencia sanitaria de urgencia, y del esfuerzo que los interesados y las propias entidades sociales han de realizar para solventar las dificultades existentes a la hora de buscar remedio para los problemas de salud que les afectan".

68 Vid., por ejemplo, la "Recomendación número 128/2014, de 29 de mayo, formulada al Ministerio de Sanidad, Servicios Sociales e Igualdad. Ministro de Sanidad, Servicios Sociales e Igualdad" donde el Defensor sostiene "La reforma operada por el citado Real Decreto-ley 16/2012 ha supuesto, más allá de su incidencia particular en determinados ámbitos, especialmente relacionados con la eficiencia del SNS, un cambio sustancial en nuestro modelo sanitario, reconduciendo su principal elemento de caracterización hacia el título de aseguramiento del sistema de Seguridad Social, en detrimento de la idea de titularidad universal del derecho a la protección de la salud y la atención sanitaria que preconizaba la anterior redacción del artículo 3 de la Ley 16/2003, de 28 de mayo, de cohesión y calidad del SNS”. Recomendación que fue rechazada. Recuperado de: https://www.defensordelpueblo.es/resoluciones/racionalizacion-del-sistemade-determinacion-del-copago-de-medicamentos-2/

${ }_{69}$ Vid., por ejemplo, la "Sugerencia, de 16 de septiembre de 2015, formulada al Ministerio de Defensa. Subsecretaría de Defensa sobre el cobro a una persona inmigrante en situación irregular por la atención sanitaria prestada en el servicio de urgencias del hospital central de la defensa Gómez Ulla de Madrid" donde el Defensor del Pueblo entiende que la factura emitida debe anularse". Sugerencia que fue rechazada. Recuperado de: https://www.defensordelpueblo.es/resoluciones/anular-la-factura-emitida-por-la-atencionprestada-a-la-interesada-en-el-servicio-de-urgencias/

${ }^{70}$ Vid., por ejemplo, la "Recomendación, de 9 de julio de 2014, formulada al Ministerio de Empleo y Seguridad Social Instituto Nacional de la Seguridad Social sobre el acceso a la prestación sanitaria del 
ciudadanos comunitarios cuando devenían irregulares ${ }^{71}$. Sin embargo, la labor de los defensores del pueblo en esta área a través de las actuaciones en materia de seguros privados podría no ser tan obvia e innegable, eso pese a que el Defensor del Pueblo viene pronunciándose regularmente ${ }^{72}$ sobre cuestiones de aseguramiento desde sus inicios ${ }^{73}$. En la mayoría de estos casos se incide en la idea de que las posibilidades de intervención de la institución son limitadas, pues la mayor parte de los problemas que se plantean son cuestiones privadas. Por esto, la labor de la Institución se centra principalmente en informar a los particulares de los derechos que les asisten, de la vía más adecuada para su defensa $^{74}$ y en procurar que la Dirección General de los Seguros y los Fondos de

sistema nacional de salud a los pensionistas por legislación suiza residentes en España cuando no tengan esta asistencia reconocida por dicho país y acrediten carecer de ingresos suficientes, al no contar estos ciudadanos con otra vía de cobertura sanitaria de carácter obligatorio" donde el Defensor del Pueblo recomienda "Restablecer el derecho a la asistencia sanitaria con cargo al Sistema Nacional de Salud a todos los perceptores de pensión de la Seguridad Social suiza, residentes en España, a los que se ha comunicado la pérdida de su condición de beneficiario, al resultarles de aplicación el artículo 3 del Real Decreto 1192/2012, de 3 de agosto, por el que se regula la condición de asegurado y de beneficiario, por no tener la consideración de personas aseguradas en Suiza y carecer de cobertura sanitaria obligatoria por otra vía. Permitir el acceso a la prestación sanitaria de la Seguridad Social, a los pensionistas por legislación suiza que residan en España, y acrediten carecer de ingresos suficientes, según lo previsto en el artículo 2.1.b del Real Decreto 1192/2012, de 3 de agosto, al no contar estos ciudadanos con otra vía de cobertura sanitaria de carácter obligatorio". Recomendación que fue rechazada. Recuperado de: https://www.defensordelpueblo.es/resoluciones/acceso-a-la-prestacion-sanitaria-del-sistema-nacional-desalud-a-los-pensionistas-por-legislacion-suiza-residentes-en-espana-cuando-no-tengan-esta-asistenciareconocida-por-dicho-pais-y-acrediten-ca-2/

${ }^{71}$ Vid., por ejemplo, la "Recomendación, de 9 de septiembre de 2018, formulada al Ministerio de Trabajo, Migraciones y Seguridad Social Secretaría de Estado de Migraciones sobre la residencia permanente de familiar de ciudadano de la Unión Europea" donde el Defensor del Pueblo expone que "Esta institución viene poniendo de manifiesto de manera reiterada las negativas consecuencias que ha tenido para los familiares de ciudadanos españoles y de la Unión Europea la entrada en vigor del Real Decreto Ley 16/2012, de 20 de abril. A juicio del Defensor del Pueblo, algunas de las medidas que contemplaba la citada norma han provocado que dichos familiares quedaran en situación de irregularidad y sin asistencia sanitaria, lo que, a su vez, genera situaciones discriminatorias para los descendientes menores de edad en la medida en que impiden el acceso del progenitor extranjero a la realización de actividades lucrativas y, por tanto, el ingreso de rentas familiares puede ser mucho menor". Recuperado de: https://www.defensordelpueblo.es/resoluciones/conceder-tarjeta-de-residencia-de-larga-duracion-de-lasprevistas-por-el-regimen-general-si-no-se-concede-la-residencia-europea/

${ }^{72}$ Es frecuente la aparición de un epígrafe en el Informe Anual del Defensor del Pueblo dedicado a los seguros

${ }^{73}$ Defensor del Pueblo. (1983). Informe Anual del Defensor del Pueblo. (punto I 4.2.4. p. 53). Recuperado de: https://www.defensordelpueblo.es/wp-content/uploads/2015/05/INFORME1983InformeyDebates.pdf Literalmente: "También son muy numerosas las quejas al Defensor del Pueblo de personas que, pese a tener pólizas de seguros en vigor, contratadas con diversas entidades aseguradoras, han visto defraudado su derecho al percibo de la indemnización pactada, por haber entrado en quiebra o desaparecido la empresa contratante, pese a la vigilancia que incumbe al Ministerio de Economía y Hacienda. En algunos casos denunciados se han producido situaciones de particular gravedad para los asegurados."

${ }^{74}$ Defensor del Pueblo. (2010). Informe Anual del Defensor del Pueblo. (pp.778 y ss). Recuperado de: https://www.defensordelpueblo.es/wp-content/uploads/2010/12/InformeAnualCortesGenerales2010.pdf 
Pensiones -en adelante DGSFP-, atienda a los ciudadanos en plazos razonables ${ }^{75}$. No obstante, algunas versan sobre posibles irregularidades administrativas por acción y omisión del órgano que tiene encomendada la competencia, la DGSFP, donde si procede la actuación. Además, "algunas de las quejas recibidas reflejan situaciones que, en ciertos aspectos, exceden del ámbito meramente privado y pueden provocar conflictos que afecten a sectores sociales especialmente desprotegidos" ${ }^{76}$, donde tienen también mayor espacio de actuación. Así ocurre en la cuestión que aquí abordamos, que ha sido mencionada expresamente en los Informes Anuales de la Institución en los años 1992, 1997, 1999, 2001, 2004, 2005, 2006, 2007, 2008, 2010, 2011 y 2014 ${ }^{77}$. De manera añadida, en aras de mejorar respuesta a este problema, al margen de los espacios de actuación ya consolidados, quizá debería plantearse la Institución la cuestión de si las compañías aseguradoras prestan servicios de interés general o realizan actividades de interés general, pues en caso de ser la respuesta afirmativa, existe doctrina ${ }^{78}$ e incluso normativa $^{79}$ que apuesta por una supervisión directa de la Institución a las empresas privadas que prestan estos servicios ${ }^{80}$.

\footnotetext{
${ }^{75}$ Defensor del Pueblo. (1999). Informe Anual del Defensor del Pueblo. (pp. 454 y ss). Recuperado de: https://www.defensordelpueblo.es/wp-content/uploads/2015/05/INFORME1999informe.pdf

${ }^{76}$ Defensor del Pueblo (1999) (2010)

77 Por la reducida extensión de esta contribución solo incidiremos en las actuaciones del Defensor del Pueblo nacional reflejadas en los Informes Anuales. No obstante, han existido otras actuaciones de defensores del pueblo autonómicos que inciden sobre esta materia. Por ejemplo: Ararteko. (2012). Los derechos de las personas consumidoras y usuarias y la prestación de servicios de interés general por empresas privadas. Colección Jornadas sobre derechos humanos; Ararteko. (2013). La protección de los derechos de las personas en sus relaciones con las entidades financieras. Colección Jornadas sobre derechos humanos.

${ }^{78}$ Ponce Solé, J. (2012). "El ejercicio privado de funciones públicas en el moderno derecho público: la supervisión por los Ombudsmen de los privados a propósito del nuevo papel del Defensor catalán". PRADPI

${ }^{79}$ Generalidad de Cataluña. Ley 24/2009, de 23 de diciembre, del Síndic de Greuges. DOGC núm. 5536 30 de diciembre de 2009. Art.26 Sujetos sometidos a supervisión. El Síndic de Greuges supervisa, en ejercicio de sus competencias, la actividad de los siguientes sujetos: (...) d) Las empresas privadas que gestionen servicios públicos o lleven a cabo, mediante concierto o concesión, actividades de interés general o universal o actividades equivalentes, así como las demás personas vinculadas contractualmente con la Administración de la Generalidad o con las entidades públicas que dependen de ésta, en los términos establecidos en el artículo 78.1 del Estatuto.

${ }^{80}$ Ibidem. Ponce Solé, J. (2012). p. 24. Sobre el art.26 de la Ley del Sindic de Greuges "No cabe descartar, además, que la supervisión se extienda no sólo a los servicios de interés (económico) general formalmente declarados como tales, sino también a otras "actividades de interés general", en la dicción literal del EAC y de la Ley. Desde luego, los servicios generales, en el sentido técnico jurídico visto, son "actividades de interés general. Pero éstas no se agotan en aquéllos, por cuanto existen actividades privadas de interés general que técnicamente no se configuran como un servicio de interés general, pero que podrían encajar en esta cláusula normativa. Pensemos en los ya aludidos servicios públicos impropios, como los denomina la doctrina jurídica española. En esta línea, cabría empezar a reflexionar sobre actividades con un impacto extraordinario en el interés general y con una amplia regulación administrativa sin duda son actividades privadas de interés general, como podría ser el caso de las entidades bancarias (en este sentido, téngase en cuenta, por ejemplo, el caso de las entidades bancarias)"
} 
En el año 1999 se reflejaría por primera vez en el Informe Anual del Defensor del Pueblo de manera clara la cuestión central aquí abordada, las barreras en el acceso y la permanencia en los seguros de asistencia sanitaria de las personas con discapacidad. En concreto, en este documento se informa de la negativa de ofertar un seguro de asistencia sanitaria a una menor por tener Hepatitis B, y lo que es más sorprendente, de las quejas de un colegio profesional que entendía que una sociedad médica imponía a sus profesionales sanitarios determinadas prácticas tendentes a limitar el derecho de asistencia de los pacientes ${ }^{81}$.

En los años 2001 y 2004 este seguro sería únicamente mencionado para dejar constancia de la recepción de quejas que denunciaban subidas de precio abusivas en este producto. Sin embargo, en el año 2005 se volvía incidir en el centro del problema, pues el Informe Anual de la Institución en 2005 refleja cómo se estaba llevando a cabo una investigación ante la DGSFP en relación con la negativa de una determinada compañía de asistencia sanitaria a dar de alta en su seguro a la interesada, su marido e hijo por tener este último, Síndrome de Down. El Defensor del Pueblo iría esta vez más allá de la mera transmisión de esta información y aseveraría lo siguiente "cierto es que, para las entidades aseguradoras, la contratación de un seguro de asistencia sanitaria tiene un carácter voluntario y entra en el ámbito de la actividad aseguradora privada, que se rige por el principio de libertad de mercado, si bien con sujeción a la normativa reguladora de tal actividad (...). Ha de tenerse en cuenta, por otra parte, que, dentro del ámbito de la técnica aseguradora, corresponde a la entidad efectuar una valoración del riesgo a fin de valorar la viabilidad de su asunción y la determinación de las condiciones, entre otras económicas, que otorga el seguro. Puede suceder que las contingencias o sucesos cubiertos no sean asegurables o carezcan de experiencia actuarial o estadística siendo la tarificación imposible o no pueda medir los riesgos sin las probabilidades de ocurrencia o predecir el coste futuro de los posibles siniestros. Sobre la base de estos argumentos, la Dirección General de Seguros y Fondos de Pensiones informó de que la entidad denunciada cuenta con suficiente experiencia, para poder tarificar los riesgos a los que puede dar lugar la cobertura de un asegurado que padezca un determinado síndrome, por lo que debería proponer al cliente un determinado importe de la prima para que éste decidiera contratar o no el seguro. Se destacaba que, en cualquier caso, el centro directivo viene realizando las actuaciones oportunas con las entidades de seguros de asistencia sanitaria, para ponerles de manifiesto que siendo entidades autorizadas para contratar seguros que cubran los riesgos derivados de la asistencia sanitaria, no pueden establecer discriminaciones en el desarrollo de sus funciones. Lo que ha de entenderse con independencia de que la valoración del riesgo influya en la tarificación y que el

\footnotetext{
${ }^{81}$ No obstante, en el año 2011, se seguían denunciando públicamente las discriminaciones por Hepatitis B en el ámbito de los seguros de salud. Vide. Rincón, R. (15 de diciembre 2011). "Hacienda embarga a un enfermo de SIDA por no pagar el tratamiento". El País. Recuperado de: https://elpais.com/sociedad/2011/12/15/actualidad/1323919480 711576.html
} 
padecimiento de determinados síndromes puede afectar a las coberturas contratadas y a las condiciones particulares del contrato que se suscribe. Si bien lo anterior no puede suponer, en ningún caso, una barrera que impida de manera previa el acceso a un determinado tipo de contrato, con el que se pretendía complementar la asistencia pública de salud y permitir el derecho a la protección de la salud al que alude el artículo 43 de la Constitución". A la vista de esta conclusión, aparece en el mismo informe el compromiso de seguimiento de los avances que se produjesen "como consecuencia de dichas actuaciones con las entidades de seguros de asistencia sanitaria, así como de las medidas que se adopten o estén previstas adoptar para evitar dicha discriminación, y garantizar el derecho a la igualdad de oportunidades a las personas con discapacidad".

Siguiendo esta estela, el Informe del año 2006 expondría las soluciones encontradas a este problema. Sobre éstas se dice que la DGSFP remitió un informe realizado por una mutualidad de previsión social, en el que reflejaba los tipos de seguros ofrecidos para las personas que tienen Síndrome de Down. Al margen de estas soluciones, se refleja la queja planteada por una persona con diabetes a la que le fue denegada la contratación de este seguro, habiendo remitido la DGSFP en respuesta a esta cuestión un "Convenio marco de colaboración entre las diversas entidades aseguradoras y organizaciones sin ánimo de lucro comprometiéndose (...) a la creación de un seguro (...) con las mismas condiciones técnicas y económicas que las personas que no son diabéticas".

En el año 2007, no se retomaría de manera directa esta cuestión, pero a propósito de la petición de modificación del artículo 83 de la Ley 50/1980, de 8 de octubre, de Contrato de Seguro -en adelante LCS-, que exceptúa la posibilidad de contratar un seguro para caso de muerte de menores de catorce años de edad o incapacitados, la Dirección General de Coordinación de Políticas Sectoriales sobre Discapacidad informaría a la defensoría de con motivo del desarrollo reglamentario de la Ley 51/2003, de 2 de diciembre, de Igualdad de oportunidades, no discriminación y accesibilidad universal de las personas con discapacidad se tenía la intención de colaborar con la DGSFP para revisión de las normas sobre los seguros privados, con el fin de suprimir cualquier tipo posible de discriminación hacia las personas con discapacidad a la hora de contratar seguros.

En estos años, de manera paralela, también se publicarían dos documentos que contribuirían al análisis de esta cuestión. El primer documento, denominado "La discriminación por razones de discapacidad en la contratación de seguros” fue publicado por el Comité Español de Representantes de Personas con Discapacidad -CERMI- en 2004 y hace una evaluación de la discriminación de las personas con discapacidad en relación con el sector seguro ${ }^{82}$. El segundo, titulado "El acceso de las personas que viven

${ }^{82}$ Pérez Bueno, L. (2004) La discriminación por razones de discapacidad en la contratación de seguros. CERMI. Recuperado de: http://riberdis.cedd.net/bitstream/handle/11181/3843/discriminacion_por_razones_de_discapacidad_contr atacion_de_seguros.pdf?sequence $=1 \&$ rd $=0031400140217676$ 
con VIH/SIDA a los servicios de seguro y otros servicios financieros conexos. Análisis de la situación presente y propuestas", publicado por CESIDA en 2008, llegaría a la conclusión de que la negativa a asegurar a una persona únicamente por tener VIH puede ser considerada discriminatoria, y como tal ilícita, si no cuenta con el suficiente respaldo actuarial.

Sin embargo, pese a estas actuaciones y la entrada en vigor de la CDPD en el año 2008, la primera modificación legislativa tendente a eliminar la discriminación en el acceso a los contratos de las personas con discapacidad se produciría en el año 2011 con la aprobación de la Ley 26/2011, de 1 de agosto, de adaptación normativa a la Convención Internacional sobre los Derechos de las Personas con Discapacidad -en adelante Ley 26/2011-. Esta normativa acogería literalmente la propuesta que haría el CERMI en el documento antes mencionado e introduciría una Disposición Adicional Cuarta en la LCS que prohíbe "la denegación de acceso a la contratación, el establecimiento de procedimientos de contratación diferentes de los habitualmente utilizados por el asegurador o la imposición de condiciones más onerosas, por razón de discapacidad, salvo que se encuentren fundadas en causas justificadas, proporcionadas y razonables, que se hallen documentadas previa y objetivamente".

A ese mismo año, el 2011, corresponde el Informe Anual más reciente que incide en la materia. En éste se plasmaría la queja planteada por la Comisión Ciudadana Antisida en relación con la negativa de las compañías de seguros a dar cobertura en sus pólizas de seguros de vida y de asistencia sanitaria a personas que tienen VIH/SIDA, a la que se respondería literalmente con la misma argumentación usada en 2005. La institutición ya había trabajado de manera previa en este campo, prueba de ello es que Miguel Aguilar ${ }^{83}$ ya había afirmado en 2010 con ocasión de las Jornadas "VIH y estigma en Europa" que "recientemente se había planteado la situación relativa a los seguros privados de vida y salud, que excluyen la cobertura a las personas con VIH (...) (cuestión que) incide negativamente en sus esferas social, laboral y de salud. (...) el rechazo y la ignorancia han motivado no pocas situaciones representativas de estigma y discriminación en personas con VIH y que aún subsisten prácticas discriminatorias que exigen un esfuerzo de la sociedad para la protección de los derechos" 84 . Por esto, entendemos que quizá la Institución podría haber aportado un plus a la respuesta de 2005.

Quizá con ese plus se hubiese contribuido a la queja que la misma actora, la Comisión Ciudadana Antisida ${ }^{85}$, en conjunción con la asociación navarra SARE y algunos

\footnotetext{
${ }^{83}$ Defensor Adjunto en el momento de las declaraciones

${ }^{84}$ Defensor del Pueblo. (2010). "Manuel Aguilar interviene en las Jornadas "VIH y estigma en Europa"," El Defensor al día, $n^{\circ} 66$

${ }^{85}$ Congreso de los Diputados. Diario de sesiones del congreso de los diputados de 4 de abril de 2017. Recuperado de: http://www.congreso.es/public_oficiales/L12/CONG/DS/PL/DSCD-12-PL45.PDF\#page $=4$ pag 6 
individuales ${ }^{86}$, presentaron ante el Defensor del Pueblo Navarro a principios del año $2010^{87}$. Queja que derivaría en una sugerencia ${ }^{88}$ al Departamento de Asuntos Sociales, Familia, Deporte y Juventud, para que constatase de forma fehaciente, en colaboración con las asociaciones que trabajan en el campo del VIH/SIDA, si existían prácticas aseguradoras discriminatorias por razón de $\mathrm{VIH}^{89}$. Sugerencia que fue aceptada por el Departamento que pidió a la DGSFP que determinara si las cláusulas contractuales por las que se excluye de la cobertura de las citadas pólizas a las personas con VIH podían considerarse abusivas o discriminatorias. Sin embargo, el informe de la DGSFP no sería concluyente pues consideraba que el carácter abusivo de una cláusula debe ser apreciado por el juez, considerando la naturaleza, el conjunto de cláusulas del contrato y las demás circunstancias concurrentes. A pesar de este informe, el Departamento consideró de forma positiva la eliminación de estas condiciones, lo que derivaría en una Proposición de Ley para la modificación del texto refundido de la Ley General para la Defensa de los Consumidores y Usuarios y otras leyes complementarias, aprobado por Real Decreto Legislativo 1/2007, de 16 de noviembre -en adelante TRLGDCU- que en líneas generales establecía la nulidad de las clausulas que discriminasen a una de las partes por razón de VIH y preveía la extensión de esta previsión a otras condiciones de salud que sufriesen los mismos efectos excluyentes. Esta propuesta fue votada y aprobada por unanimidad para su remisión a la Mesa del Congreso a tenor de lo dispuesto en el artículo 212 del Reglamento del Parlamento de Navarra en $2011^{90}$. Sin embargo, la Mesa del Congreso de los Diputados declaró caduca la iniciativa al finalizar la Legislatura en 2011 y el Congreso la rechazaría por mayoría absoluta en $2013^{91}$. No obstante, en el año 2015 se seguía

\footnotetext{
${ }^{86}$ Ibarra, A. (9 de agosto 2010). "El VIH es una enfermedad crónica y la esperanza de vida no es menor". Diario de Noticias de Navarra. Recuperado de: https://www.siis.net/documentos/hemeroteca/1008093.pdf 87 Defensor del Pueblo de Navarra. (2010). Informe anual. Recuperado de: http://www.parlamentodenavarra.es/sites/default/files/boletines/B2011806-1.pdf

${ }^{88}$ Sobre el funcionamiento del Defensor del Pueblo Navarro véase: Enériz Olaechea, F.J. (2006). "El Defensor del Pueblo de la Comunidad Foral de Navarra." Gobierno de Navarra. Recuperado de: http://www.navarra.es/appsext/DescargarFichero/default.aspx?codigoAcceso=PdfRevistaJuridica\&ficher o=RJ 42 I 1.pdf

${ }^{89}$ Defensor del Pueblo de Navarra. (3 de mayo 2010). "El Defensor del Pueblo de Navarra sugiere al Departamento de Asuntos Sociales que investigue y erradique posibles prácticas discriminatorias de las compañías aseguradoras a personas con VIH'. Sección de noticias. Recuperado de: http://www.defensornavarra.com/index.php/es/Noticias/2007-2012/2010/El-Defensor-del-Pueblo-de-

Navarra-sugiere-al-Departamento-de-Asuntos-Sociales-que-investigue-y-erradique-posibles-practicasdiscriminatorias-de-las-companias-aseguradoras-a-personas-con-VIH

${ }^{90}$ Parlamento de Navara. (24 de marzo 2011). Diario de la sesión plenaria del núm. 71. Recuperado de: http://www.parlamentodenavarra.es/sites/default/files/diarios-sesiones/diario-sesiones-Plen7100.pdf

${ }^{91}$ En este punto cabe destacar la intervención de la señora Grande Pesquero en relación con el intento de eliminar la discriminación debatida en la fallida. Congreso de los Diputados. (6 de mayo 2014). Proposición de Ley relativa a la igualdad de trato y no discriminación de 2012. Diario de Sesiones del Congreso de los Diputados, num.197, p. 16-17
} 
discriminando a las personas con $\mathrm{VIH}^{92}$, Síndrome de Down ${ }^{93}$, Diabetes ${ }^{94}$ y otras condiciones de salud en los seguros. Por esto, lejos de cejar en el empeño, la Proposición de Ley volvió a ser aprobada en el Parlamento de Navarra y en enero de 2017 se volvió a presentar al Congreso de los Diputados, dando fruto a la Ley 4/2018, de 11 de junio, por la que se modifica el texto refundido de la Ley General para la Defensa de los Consumidores y Usuarios y otras leyes complementarias, aprobado por Real Decreto Legislativo 1/2007, de 16 de noviembre -en adelante Ley 4/2018-, demostrándose así la autoridad de los defensores del pueblo en la garantía objetiva de los derechos.

Sin embargo, esta ley también ha demostrado lo incontrolable del proceso legislativo, pues no solo tuvo que llegar tres veces la propuesta a las Cortes Generales para ser aprobada, sino que habiendo partido de la intención de modificar el TRLGDCU para prohibir las cláusulas que excluyesen a una de las partes por razón de VIH/SIDA y la propuesta de extender esta previsión a "otras enfermedades respecto a las que pueda considerarse que se aplican los mismos efectos excluyentes en las relaciones jurídicas", se ha llegado a un texto que se prevé la prohibición inicial pero extiende la protección a las personas que tengan "otras condiciones de salud" pero que sigue reservando la posibilidad de extender la protección a "otras enfermedades respecto a las que pueda considerarse que se aplican los mismos efectos excluyentes en las relaciones jurídicas", generando inseguridad sobre si el término más amplio "otras condiciones de salud" podría modificarse por uno más restrictivo. Además, con el pretexto de "anticipar los últimos avances comunitarios sobre la materia" se ha unido la modificación del TRLGDCU con una modificación de la LCS que pese a pretender "garantizar la existencia de un adecuado aseguramiento sin discriminar a aquellas personas con VIH/SIDA (u otras condiciones de salud)" lo que hizo fue copiar la Disposición Adicional Cuarta de la LCS que prohíbe "la denegación de acceso a la contratación, el establecimiento de procedimientos de contratación diferentes de los habitualmente utilizados por el asegurador o la imposición de condiciones más onerosas, por razón de discapacidad, salvo que se encuentren fundadas en causas justificadas, proporcionadas y razonables, que se hallen documentadas previa y objetivamente" cambiando "discapacidad" por "VIH u otras condiciones de salud". Disposición que ya había sido muy cuestionada pues su límite "salvo que se encuentren fundadas en causas justificadas, proporcionadas y razonables, que se hallen documentadas previa y objetivamente" dificulta la consecución del objetivo

\footnotetext{
${ }_{92}$ Ramiro Avilés, M. (2015). Discriminación por razón del VIH: los casos de la clínica legal en 2015. CESIDA. Recuperado de: https://www.cesida.org/wpcontent/uploads/2013/09/ClinicaLegal_informeCasosDiscriminacionVIH2015.pdf

${ }^{93}$ Gonzalez Carrasco, M. (2015). "La vida no va de cromosomas: A propósito del aseguramiento de la sanidad privada de los discapacitados". Revista CESCO

${ }^{94}$ En el año 2016, la Federación Española de Diabetes -FEDE- cerraría con una compañía aseguradora un acuerdo para ofrecer el primer seguro de salud que ofrece ventajas y condiciones exclusivas para personas con diabetes. Recuperado de: http://productosyserviciosfede.es/seguros-de-salud/. Para estudiar la cuestión desde la perspectiva de los interesados en la contracción, consúltese: https://www.acierto.com/segurossalud/diabeticos/
} 
pretendido, la prohibición de la discriminación por discapacidad, VIH u otras condiciones de salud en el proceso asegurador. Con esto se ha provocado no solo una mezcolanza de regímenes -consumidores y contrato de seguro- creados para distintos destinatarios ${ }^{95} \sin$ referencia alguna en el título de la normativa ${ }^{96}$, sino que se lea la reafirmación del citado límite como "inequívoca voluntad de restringir al máximo el alcance de esta excepción ${ }^{97}$ a la regla general" 98 . Este panorama se emborrona aún más si cabe cuando desde las instituciones, como el Sindic de Greuges de Catalunya, se suscribe una simple referencia a esta medida como "prohibición de la discriminación por razón de VIH/SIDA" dentro del Diagnóstico del Plan de Derechos Humanos de Cataluña ${ }^{99}$.

También cabe destacar que, en los años 1992, 1997 y 2014, pese a que no se hizo mención expresa del seguro de asistencia sanitaria, otro seguro, el de decesos, sí que fue mencionado $^{100}$. Quizá el vínculo entre un seguro de decesos y la protección de la salud no sea evidente, pero lo cierto es, que hoy en día muchas compañías de seguros ofrecen dentro de este producto la cobertura de accidente y/o grave enfermedad repentina fortuita y aguda producida en el extranjero. Sobre este producto en el año 1992 se denunció ante el Defensor del Pueblo las importantes subidas que habían sufrido estas pólizas, entrando en contacto la Institución con la Dirección General de Seguros para la búsqueda de una solución. En el año 1997, la cuestión vuelve a aparecer en el Informe Anual de la Institución, donde ésta preocupada por el cumplimiento de los principios de equidad y suficiencia de la prima pide a la Dirección General de Seguros que imprima la mayor diligencia posible al estudio sobre posibles modificaciones en el cálculo de estas primas

\footnotetext{
${ }^{95}$ Recordemos que un consumidor es una persona física que actúa con fines ajenos a su actividad comercial, empresarial, oficio o profesión. Por lo tanto, es posible contratar un seguro y no ser consumidor.

${ }^{96}$ Sobre esto nos remitimos a la publicación de García-Escudero Márquez, P. (2005). Nociones de técnica legislativa para uso parlamentario. Asamblea: revista parlamentaria de la Asamblea de Madrid. p.146-147, que diría: "El nombre de la ley es la parte del título que indica su objeto, que permite identificar su contenido esencial y distinguirla de las demás leyes. La indicación del objeto de la ley debe ser precisa y completa, pero también breve y concreta. Cuando la ley tenga por objeto la modificación de otra ley anterior, deberá indicarse así en el título, citando por su título completo la ley modificada."

${ }^{97}$ Siendo la regla general la libertad contractual y la excepción la prohibición de discriminación por razón de discapacidad, VIH u otras condiciones de salud.

${ }^{98}$ Gómez Acebo Pombo. (2018). Boletín de Seguros N. ${ }^{\circ}$ 12. Recuperado de: https://www.ga-p.com/wpcontent/uploads/2018/08/boletin-de-seguros-12.pdf

99 Serra Perelló, P. Mansilla Jacas, T. (2018). Drets del col-lectiu LGTBIQ. Diagnosi del Pla de drets humans de Catalunyar Sindic. p.14 Recuperado de: http://www.sindic.cat/site/files/480/Drets\%20del\%20colectiu\%20LGTBIQ.pdf

${ }^{100}$ En el Informe Anual 2001 se abordaría la cuestión tanto de los seguros de asistencia sanitaria como de decesos, pero esta contribución, al igual que la del año 2004, únicamente acogería de manera genérica las quejas planteadas en torno a esta problemática. El Informe Anual del Defensor del Pueblo del año 2001 dice lo siguiente: "los seguros de asistencia sanitaria siguen provocando quejas en las que los afectados denuncian supuestos incumplimientos contractuales o subidas de precios que consideran abusivas, especialmente cuando los asegurados son personas de edad avanzada. En estos casos se les informa de la posibilidad de reclamar ante la Dirección General de Seguros y Fondos de Pensiones, así como de acudir a la vía judicial, dado el carácter privado de estos problemas. Igual circunstancia se produce con los seguros de decesos en cuanto al aumento de primas, debido en buena medida al incremento de los precios de los servicios funerarios."
} 
con la finalidad de garantizar los derechos de los asegurados, pues el colectivo más numeroso afectado por la incidencia de este seguro, por su edad y condiciones, es un grupo especialmente sensible. Sin embargo, el Informe Anual de la Institución en el año 2014 muestra como el problema continuaba presente. En este informe el Defensor del Pueblo, al hilo de la recomendación $14010382^{101}$, recuerda que "el seguro de decesos se considera un seguro de riesgo, no de personas y, por tanto, no recibe el trato de un seguro de vida, no es capitalizable, rescatable ni transmisible, dando como resultado clientes cautivos, restringiendo la voluntad de cambiar de entidad aseguradora, lo que genera gran disconformidad entre los suscriptores. Este problema se debe a la insuficiencia normativa específica sobre esta modalidad aseguradora, siendo de aplicación únicamente el título III de la Ley del Contrato de Seguro, que regula de forma genérica los seguros de personas. $\mathrm{Al}$ carecer de una normativa concreta, existen lagunas que afectan negativamente a los asegurados". Como resultado de la actuación de oficio ante la DGSFP se informó que se preveía una reforma en la Ley de Contrato de Seguro enmarcada en el anteproyecto de Ley del Código Mercantil ${ }^{102}$.

Después de este breve repaso a la labor del Defensor del Pueblo en cuanto al acceso y la permanencia de las personas con discapacidad en los seguros de salud privados, no cabe duda de que los ciudadanos han hecho a esta Institución conocedora de la persistencia de los problemas en esta área y de que ésta ha defendido siempre un acceso a los seguros de salud sin discriminación debido a su inexorable relación con el derecho a la protección de la salud contemplado en el artículo 43 de la CE. Sin embargo, solo se han realizado una recomendación y una sugerencia en esta materia, por parte del Defensor del Pueblo Estatal y del Defensor del Pueblo Navarro respectivamente. Si tenemos en cuenta la naturaleza persuasiva de las actuaciones de esta Institución y que estas dos actuaciones han dado como fruto avances legislativos en la dirección apuntada, no puede sino defenderse la conveniencia de realizar una de estas actuaciones cuando se tenga la próxima oportunidad, pues mientras las quejas se desvanecen la argumentación de estas

101 Defensor del Pueblo. (2014). Queja 14010382. Recuperado de: https://www.defensordelpueblo.es/resoluciones/normativa-de-los-seguros-de-decesos-2/

${ }^{102}$ Nótese que pese a no haber sido aun aprobada la Propuesta de Código Mercantil, con ocasión de la
aprobación de la Ley $20 / 2015$, de 14 de julio, de ordenación, supervisión y solvencia de las entidades
aseguradoras y reaseguradoras, se introdujo el artículo 106 bis en la Ley $50 / 1980$, de 8 de octubre, de
Contrato de Seguro con igual redacción a la reflejada en la propuesta y el Informe del Defensor del Pueblo.
Es más, la "Propuesta de la Sección Segunda, de derecho mercantil del Anteproyecto de Ley de Código
mercantil tras el dictamen del Consejo de Estado" de marzo del año 2018 ahonda aún más en la exigencia
de "incluir el sistema que se utilice para el cálculo y actualización de las primas del seguro de decesos, para
evitar la incertidumbre que crea a los clientes" reemplazando el punto 5 del artículo 106 bis de la actual
Ley 50/1980, de 8 de octubre, de Contrato de Seguro por el siguiente "en caso de prórroga la prima será
objeto de adecuado reajuste conforme a los nuevos costos de la cobertura; de no producirse acuerdo
respecto del reajuste de la prima la cobertura se mantendrá en idénticos términos a los aplicados con
anterioridad a la prórroga". No puede decirse que se esté previendo la introducción de un sistema que
elimine la incertidumbre de los clientes, pero al contemplarse el límite de "conforme a los nuevos costos
de la cobertura" la incertidumbre queda cuanto menos reducida. 
actuaciones más sólidas parece permanecer. Además, la institución podría aprovechar la oportunidad para ahondar de manera más profunda en una argumentación que inició ya hace más de veinte años, coadyuvando así a un fin tan codiciado dentro y fuera de nuestras fronteras.

Para terminar, cabe destacar que los pronunciamientos de esta Institución pueden ser utilizados como argumento en sede judicial para sustentar la posición de las partes y que, existen casos donde efectivamente el órgano judicial ha fallado en consonancia con estos $^{103}$. En este caso ha expirado el plazo para la presentación de un recurso de inconstitucionalidad que permitiese enjuiciar la constitucionalidad de la Ley 4/2018 -e incluso la Ley 26/2011 104 -. No obstante, esto no quiere decir que las posibilidades de que el TC revise la norma hayan sido agotadas, pues un proceso en el que se use ésta podría derivar en un recurso de amparo aparejado o no a una autocuestión de inconstitucionalidad e incluso en una cuestión de constitucionalidad. Sin ánimo de exhaustividad podríamos apuntar uno de esos casos prácticos susceptibles de llegar a amparo o de elevación al TC mediante una cuestión de inconstitucionalidad. Este sería el caso de una persona a la que se le deniega el acceso a un seguro por razón de salud alegando la compañía para tal rechazo la mera falta de cálculos actuariales ${ }^{105}$, si tenemos en cuenta que las DA $4^{\mathrm{a}}$ y $5^{\mathrm{a}}$ LCS permiten denegar el acceso a la contratación si esta se encuentra fundada "en causas justificadas, proporcionadas y razonables, que se hallen documentadas previa y objetivamente" podríamos plantearnos ¿cuáles serían las consecuencias de aceptar la falta de cálculos actuariales como motivo válido para cumplir con lo previsto en las disposiciones mencionadas? ¿es esta excepción compatible con la obligación de los poderes públicos de establecer medios de protección eficaces frente a

\footnotetext{
${ }^{103}$ Entre otras: Sentencia n ${ }^{\circ}$ 268/2018 del Juzgado de lo Contencioso-Administrativo ${ }^{\circ} 14$ de Madrid en el Procedimiento Abreviado no 140/2018. Expone en su fundamento jurídico segundo: "Por lo que denegar una autorización de residencia por razones meramente económicas, como sucede en el presente caso, implica una situación de discriminación que vulnera el derecho a vivir en familia de los ciudadanos españoles, y que igualmente es dictada sin tener en cuenta la propia Recomendación del Defensor del Pueblo realizada a la Secretaría General de Inmigración, que ya alertaba de esta situación de discriminación y que, por tanto, están vulnerando derechos recogidos tanto en la Constitución Española como en el Convenio Europeo para la Protección de los Derechos Humanos y las Libertades Fundamentales. En este sentido, la consecuencia de la aplicación de los requisitos del ap. 1 del Art. 7 del RD 240/2007 es la posibilidad de que los familiares de los ciudadanos comunitarios pase a encontrarse en situación irregular en España si no acreditan sus cónyuges comunitarios, dichos requisitos y que se exigen para la residencia superior a tres meses, provocando con ello la existencia de una categoría de españoles ilícitamente discriminados por la circunstancia de que sus esposos/esposas no puedan residir legalmente en el Reino de España, mediante la introducción de restricciones como la que nos ocupa, de orden económicos (ingresos y seguro de enfermedad), sin perjuicio de la realidad social de crisis económica generalizada presente en España. Considerando igualmente que el Defensor del Pueblo, recientemente, ha emitido una importante recomendación a la Secretaría General de Inmigración y Emigración en la que considera que "Se ha producido pues una diferencia de trato en categorías de personas, (cónyuges de ciudadanos españoles) en situaciones subjetivas equiparables (matrimonio civil inscrito en el Registro Civil ...)."

${ }^{104}$ Puesto que la DA $4^{\mathrm{a}}$ y $5^{\mathrm{a}}$ de la LCS al ser gemelas adolecen de los mismos fallos.

${ }^{105}$ La ciencia actuarial es la disciplina encargada de la determinación del riesgo de un determinado perfil y la generación de una prima de seguro ajustada a éste.
} 
las violaciones de los derechos fundamentales entre particulares? En el primer caso, si el órgano judicial entendiese que la ausencia de cálculos es una alternativa válida para cumplir la condición impuesta en la disposición, podría argumentarse en amparo que con esa interpretación el órgano judicial ha violado el artículo $15 \mathrm{CE}$ en conexión con los artículos 10.1 y $14 \mathrm{CE}$ al haber vaciado de contenido disposiciones tendentes a evitar diferenciaciones atentatorias contra la dignidad y vejatorias. En el segundo caso y en el supuesto de que del recurso de amparo se derive una autocuestión de inconstitucionalidad, el órgano judicial podría entender que la salvedad introducida por la Disposición Adicional $5^{\mathrm{a}}$-y por analogía $4^{\mathrm{a}}$ - de la LCS por su amplitud impide diferenciar aquellos supuestos que son vejatorios y atentatorios contra la dignidad por discriminatorios y los que no lo son y esto constituye un incumplimiento del deber de los poderes públicos de establecer medios de protección eficaces frente a las violaciones de los derechos fundamentales entre particulares ${ }^{106}$. En ambos casos, para sustentar una interpretación restrictiva del límite de la norma e incluso su inconstitucionalidad, podría utilizarse la posición mantenida por los defensores del pueblo que defiende que si bien es cierto que para las aseguradoras la contratación de un seguro de asistencia sanitaria tiene un carácter voluntario, no es menos cierto que estás están sujetas a la normativa reguladora de la actividad -entre ellas DA $4^{\mathrm{a}}$ y $5^{\mathrm{a}}$ LCS- y que para una entidad con suficiente experiencia actuarial la alegación de ausencia de cálculos no puede suponer "una barrera que impida manera previa el acceso a un determinado tipo de contrato, con el que se pretendía complementar la asistencia pública de salud y permitir el derecho a la protección de la salud al que alude el artículo 43 de la Constitución".

\section{Conclusiones}

No cabe duda de que los cimientos del derecho a la protección de la salud propugnado por el artículo 43 de la $\mathrm{CE}$ se han tambaleado en los últimos tiempos gracias a la inestabilidad política. Ante la existencia de un riesgo, la no cobertura de un tratamiento o procedimiento médico por el sistema de salud público no es extraño que las personas utilicen los medios de los que disponen para reducirlo, en este caso, los seguros de salud privados. Sin embargo, actualmente no todas las personas pueden acceder a un seguro de salud privado por razón de discapacidad. Esta situación ha sido denunciada tanto en instancias nacionales como internacionales y se ha tratado de corregir en textos como la CDPD y la Agenda 2030. La realidad en España demuestra como el Defensor del Pueblo venía haciéndose eco de las quejas ciudadanas sobre esta materia desde el año 1999 y pronunciándose a favor de la eliminación de las barreras en el acceso a estos productos para una mejor garantía del derecho a la protección de la salud. No obstante, los primeros cambios relevantes no ocurren hasta 2011 y estos no logran acoger las demandas de todos lo que lleva a la presentación de quejas que finalmente tienen acogida parcial en la Ley

106 Alfaro Águila-Real, J. (1993). “Autonomía privada y derechos fundamentales”. ADC. Pp.58 y ss. 
4/2018. Demostrando esto que el Defensor del Pueblo tiene efectivamente un rol activo para la mejor garantía de los derechos fundamentales, lo que es esencial para la consecución de los objetivos plasmados en la Agenda 2030, pero demostrando también la importancia que tiene la conversión de las quejas en sugerencias o recomendaciones. Quizá esto debería ser una llamada para replantear cómo podría actuarse la próxima vez que una queja sobre esta materia llegue a la institución o quizá simplemente el legislador podría replantearse realizar un análisis más profundo de los informes presentados por el Defensor del Pueblo.

\section{Bibliografía}

\subsection{Legislación}

ONU. Declaración Universal de los Derechos Humanos. Adoptada y proclamada por la Asamblea General en su resolución 217 A (III), de 10 de diciembre de 1948.

ONU. Pacto Internacional de Derechos Económicos, Sociales y Culturales. Adoptado y abierto a la firma, ratificación y adhesión por la Asamblea General en su resolución 2200 A (XXI), de 16 de diciembre de 1966.

ONU. Convención sobre los derechos de las personas con discapacidad, hecho en Nueva York el 13 de diciembre de 2006.

Consejo de Europa. Convenio Europeo para la Protección de los Derechos Humanos. Hecho en Roma el 4 de noviembre de 1950.

Consejo de Europa. Carta Social Europea. Hecha en Turín de 18 de octubre de 1961.

Unión Europea. Carta de los Derechos Fundamentales de la Unión Europea. Diario Oficial de la Unión Europea, 18 de diciembre de 2000, C 364/1.

Unión Europea. Directiva del Consejo 2004/113/CE de 13 de diciembre de 2004 por la que se aplica el principio de igualdad de trato entre hombres y mujeres al acceso a bienes y servicios y su suministro. Diario Oficial de la Unión Europea, 21 de diciembre de 2004, L 373/37.

Constitución Española. Boletín Oficial del Estado, 29 de diciembre de 1978, núm. 311.

Ley 50/1980, de 8 de octubre, de Contrato de Seguro. Boletín Oficial del Estado, 17 de abril de 1981, núm. 250.

Ley Orgánica 3/1981, de 6 de abril, del Defensor del Pueblo. Boletín Oficial del Estado, 7 de mayo de 1981, núm. 109.

Ley 14/1986, de 25 de abril, General de Sanidad. Boletín Oficial del Estado, 29 de abril de 1986, núm. 102. 
Ley 16/2003, de 28 de mayo, de cohesión y calidad del Sistema Nacional de Salud. Boletín Oficial del Estado, 29 de mayo de 2003, núm. 128.

Ley 51/2003, de 2 de diciembre, de Igualdad de oportunidades, no discriminación y accesibilidad universal de las personas con discapacidad. Boletín Oficial del Estado, 3 de diciembre de 2003, núm. 289.

Real Decreto Legislativo 1/2007, de 16 de noviembre, por el que se aprueba el texto refundido de la Ley General para la Defensa de los Consumidores y Usuarios y otras leyes complementarias. Boletín Oficial del Estado, 30 de noviembre de 1981, núm. 287.

Ley 26/2011, de 1 de agosto, de adaptación normativa a la Convención Internacional sobre los Derechos de las Personas con Discapacidad. Boletín Oficial del Estado, 2 de agosto de 2011, núm.184.

Real Decreto-ley 16/2012, de 20 de abril, de medidas urgentes para garantizar la sostenibilidad del Sistema Nacional de Salud y mejorar la calidad y seguridad de sus prestaciones. Boletín Oficial del Estado, 24 de abril de 2013, núm. 98.

Ley 20/2015, de 14 de julio, de ordenación, supervisión y solvencia de las entidades aseguradoras y reaseguradoras. Boletín Oficial del Estado, 15 de julio de 2015, núm. 168.

Ley 4/2018, de 11 de junio, por la que se modifica el texto refundido de la Ley General para la Defensa de los Consumidores y Usuarios y otras leyes complementarias, aprobado por Real Decreto Legislativo 1/2007, de 16 de noviembre. Boletín Oficial del Estado, 12 de junio de 2018, núm. 142.

Real Decreto-ley 7/2018, de 27 de julio, sobre el acceso universal al Sistema Nacional de Salud. Boletín Oficial del Estado, 30 de julio de 2018, núm. 183.

Generalidad de Cataluña. Ley 24/2009, de 23 de diciembre, del Síndic de Greuges. DOGC núm. 5536 - 30 de diciembre de 2009.

\subsection{Jurisprudencia}

Tribunal de Justicia de la Unión Europea. Asunto C-236/09, de 1 de marzo de 2011.

Tribunal Constitucional. Sentencia núm. 247/2007, de 12 de diciembre.

Tribunal Constitucional. Auto 239/2012, de 12 de diciembre.

Tribunal Constitucional. Sentencia núm. 139/2016, de 21 de julio.

Juzgado de lo Contencioso-Administrativo $n^{\circ} 14$ de Madrid. Sentencia $n^{\circ}$ 268/2018, de 11 de diciembre de 2018. 
5.3. Documentación de organizaciones públicas

Ararteko. (2012). Los derechos de las personas consumidoras y usuarias y la prestación de servicios de interés general por empresas privadas. Colección Jornadas sobre derechos humanos.

Ararteko. (2013). La protección de los derechos de las personas en sus relaciones con las entidades financieras. Colección Jornadas sobre derechos humanos

Defensor del Pueblo. (1983). Informe Anual del Defensor del Pueblo. p. 53.

Defensor del Pueblo. (1999). Informe Anual del Defensor del Pueblo. pp. 454 y ss.

Defensor del Pueblo. (2010). Manuel Aguilar interviene en las Jornadas "VIH y estigma en Europa”. El Defensor al día, 66.

Defensor del Pueblo. (2010). Informe Anual del Defensor del Pueblo. pp.778 y ss.

Defensor del Pueblo. (2012). Informe Anual: Anexo E.5. Solicitudes de intervención ante el tribunal constitucional. pp. 42-56.

Defensor del Pueblo. (2014). Recomendación número 128/2014, de 29 de mayo, formulada al Ministerio de Sanidad, Servicios Sociales e Igualdad. Ministro de Sanidad, Servicios Sociales e Igualdad.

Defensor del Pueblo. (2014). Recomendación, de 9 de julio de 2014, formulada al Ministerio de Empleo y Seguridad Social Instituto Nacional de la Seguridad Social sobre el acceso a la prestación sanitaria del sistema nacional de salud a los pensionistas por legislación suiza residentes en España cuando no tengan esta asistencia reconocida por dicho país y acrediten carecer de ingresos suficientes, al no contar estos ciudadanos con otra vía de cobertura sanitaria de carácter obligatorio"

Defensor del Pueblo. (2015). Informe: Las urgencias hospitalarias en el sistema nacional de salud: derechos y garantías de los pacientes. Estudio conjunto de los defensores del pueblo.

Defensor del Pueblo. (2018). Informe Anual. Pág.409 - 410

Defensor del Pueblo. Recomendación. (2018). de 9 de septiembre de 2018, formulada al Ministerio de Trabajo, Migraciones y Seguridad Social Secretaría de Estado de Migraciones sobre la residencia permanente de familiar de ciudadano de la Unión Europea.

Defensor del Pueblo. Sugerencia, de 16 de septiembre de 2015, formulada al Ministerio de Defensa. Subsecretaría de Defensa sobre el cobro a una persona inmigrante en situación irregular por la atención sanitaria prestada en el servicio de urgencias del hospital central de la defensa Gómez Ulla de Madrid. 
OMS. (2003). Informe sobre la Salud en el Mundo 2003.

ONU. (2015). Objetivos de Desarrollo del Milenio. Informe 2015.

ONU. (2015). Resolución A/RES/70/1 aprobada por la Asamblea General el 25 de septiembre de 2015.

ONUSIDA, OMS, UNHR. (2009). Disability and HIV policy brief.

ONU. (2000). E/C.12/2000/4, CESCR Observación General 14

Tribunal Europeo de los Derechos Humanos. (2015). Thematic report: Health-related issues in the case-law of the European Court of Human Rights. Consejo de Europa.

Unión Europea. (2003). Propuesta de Directiva del Consejo por la que se aplica el principio de igualdad de trato entre mujeres y hombres al acceso a bienes y servicios y su suministro $\{$ SEC (2003) 1213\}.

Unión Europea. (2008). Propuesta de Directiva del Consejo por la que se aplica el principio de igualdad de trato entre las personas independientemente de su religión o convicciones, discapacidad, edad u orientación sexual. "2. Consulta de las partes interesadas y evaluación de impacto". \{SEC(2008) 2180\} \{SEC(2008) 2181\}.

Unión Europea. (2009). Decisión del Consejo 2010/48/CE de 26 de noviembre de 2009 relativa a la celebración, por parte de la Comunidad Europea, de la Convención de las Naciones Unidas sobre los derechos de las personas con discapacidad. Diario Oficial de la Unión Europea, L 23/35.

Unión Europea. (2012). Directrices sobre la aplicación de la Directiva 2004/113/CE del Consejo a los seguros, a la luz de la sentencia del Tribunal de Justicia de la Unión Europea en el asunto C-236/09 (Test-Achats), C 11/1.

Unión Europea. (2015). Informe de la Comisión al Parlamento Europeo, al Consejo y al Comité Económico y Social Europeo: Informe sobre la aplicación de la Directiva 2004/113/CE del Consejo, por la que se aplica el principio de igualdad de trato entre hombres y mujeres al acceso a bienes y servicios y su suministro. COM (2015) 190 final

Unión Europea. (2018) Outcome of the 3625th Council meeting Employment, Social Policy, Health and Consumer Affairs Employment, Social Policy and Health issues.

Unión Europea. Resolución legislativa del Parlamento Europeo, de 2 de abril de 2009 sobre la Propuesta de Directiva del Consejo por la que se aplica el principio de igualdad de trato entre las personas independientemente de su religión o convicciones, discapacidad, edad u orientación sexual. (COM(2008)0426). 
5.4. Documentación de organizaciones privadas

Amnistía Internacional. (2018). España: Cuatro meses después del nuevo decreto sobre sanidad universal se deben abordar sus fallos y ambigüedades. Amnistía Internacional.

REDER. (2018). Es urgente garantizar la sanidad universal. No dejar nadie atrás. REDER

\subsection{Doctrina}

Alfaro Águila-Real, J. (1993). “Autonomía privada y derechos fundamentales”. ADC. pp.58 y ss.

Arrese Iriondo, M. N. (2016). “Competencia de las Comunidades Autónomas en materia de sanidad y asistencia sanitaria a las personas migrantes en situación irregular”. Revista Aragonesa de Administración Pública. pp. 215-222

Celi Maldonado, A. (2018). La interpretación de los derechos sociales por el Defensor del pueblo. Tirant lo Blanch. pp.309-416.

Centenera Sánchez-Seco, F. (2017). "Las acciones de las defensorías del pueblo sobre el acceso de los inmigrantes en situación irregular a la asistencia sanitaria: a propósito de los análisis sobre la racionalidad normativa”. pp.109-124. En Escobar Roca, G. (2017). Ombudsman y Colectivos en situación de vulnerabilidad. Tirant lo Blanch.

Christianson, D., Beal, R., Deutscher, H., Gill, A., Koenig, W., Reese, T., Samoff, P. (1990). "The financial implications of aids for life insurance companies in the united states". Transactions of Society of Actuaries vol. 42.

Cidoncha Martín, A. (2006). La libertad de empresa (Derechos fundamentales y libertades públicas). Thomson Civitas. p.175.

Cruz Villalon, P. (1989). "Formación y evolución de los derechos fundamentales". Revista española de Derecho constitucional, 25. p.39.

De Voy, K. (1988). The effects of aids on the insurance industry. Tesis. Ball State University, Muncie, Indiana.

Delgado del Rincón, L. (2017). "El Defensor del Pueblo ante la desigual protección del derecho a la salud de los inmigrantes en situación irregular en el Estado Español”. (pp.185-212). En Escobar Roca, G,. (2017). Ombudsman y Colectivos en situación de vulnerabilidad. Tirant lo Blanch.

Delgado del Rincón, L. (2019). El derecho a la asistencia sanitaria de los extranjeros: limitaciones y problemas competenciales. Tirant lo Blanch. pp.43-45. 
Enériz Olaechea, F.J. (2006). "El Defensor del Pueblo de la Comunidad Foral de Navarra”. Gobierno de Navarra.

Escobar Roca, G. (2010). "Interpretación y garantía de los derechos fundamentales por el defensor del pueblo (Análisis empírico, reconstrucción dogmática y propuesta de futuro)". Teoría y Realidad Constitucional, 26. p.231.

Escobar Roca, G. (2011). Derechos sociales y tutela antidiscriminatoria. ThomsonAranzadi. p.733.

VV.AA. Escobar Roca, G (Dir.). (2006). IV Informe sobre derechos humanos: protección de la salud. Federación Iberoamericana de Ombudsman.

Escobar Roca, G. (2017). El Derecho, entre el poder y la justicia: Una introducción crítica al sistema jurídico español. Tirant lo Blanch. pp.362-367.

Escobar Roca, G. (2018). Nuevos derechos y garantías de los derechos. Marcial Pons. p.26.

Fagnart, J. (1991). Les assurances et le sida: Le SIDA, un defi aux droits. Bruylant

Fagnart, J. (1996). SIDA, assurances er vie privee. Reveu belge du dommage corporel. P.43.

Fernández Miguelez, A. Rodríguez Cuenca, A. (2013). Las defensorías del pueblo y la defensa de las personas y grupos vulnerables. pp.373 y ss. En VV.AA. Presno Linera, M.A. (2013). Protección jurídica de las personas y los grupos vulnerables. Universidad de Oviedo, Procuradora General del Principado de Asturias.

García-Escudero Marquez, P. (2005). "Nociones de técnica legislativa para uso parlamentario". (p.146-147). Asamblea: Revista parlamentaria de la Asamblea de Madrid. pp. 146-147.

Gil Payno, M. (2018). "Experiencias y desafíos de la agenda 2030 y los ODS: el índice de coherencia de políticas para el desarrollo”. p.132. En VV.AA. Escobar Roca, G. (2018). Las Defensorías del Pueblo iberoamericanas ante la Agenda 2030. PRADPI.

Gómez Acebo Pombo. (2018). Boletín de Seguros N. ${ }^{o}$ 12. GAP.

González Carrasco, M. (2015). "La vida no va de cromosomas: A propósito del aseguramiento de la sanidad privada de los discapacitados”. Revista CESCO.

Herrera Ruiz, F.J. (2009). Selección de riesgo en el seguro de salud. Tesis del Master en Dirección de Entidades Aseguradoras y Financieras. Universidad de Barcelona. 
VV.AA. Holland, D. (1988). "The impact of aids on life and health insurance companies: a guide for practicing actuaries". Transactions of Society of Actuaries vol. 40. p. 2.

VV.AA. Jiménez Sánchez, G., Díaz Moreno, A. (2013). Derecho mercantil. Vol. 9, Los contratos de seguro. Marcial Pons. pp. 2-5Lema Añón, C. (2014). "La titularidad del derecho a la salud en España: ¿hacia un cambio de modelo?’. Revista de Bioética y Derecho. pp. 3-16.

Lema Añón, C. (2018). "El derecho a la salud ante sus cuatro flagelos: mercantilización, recortes, exclusión y desigualdad. Por una ciudadanía de la salud democrática y en igualdad”. pp. 609-613. En VV.AA. Lucas, J., Rodríguez Uribes, J. Derechos Humanos y Constitución. Tirant lo Blanch.

León Alonso, M. (2009). La protección Constitucional de la Salud. La Ley. pp.149150.

Martín-Retortillo Baquer, L., de Otto, Ignacio. (1988). Derechos fundamentales y Constitución. Civitas. pp. 65 y ss.

Pérez Bueno, L. (2004) La discriminación por razones de discapacidad en la contratación de seguros. CERMI.

Ponce Solé, J. (2012). El ejercicio privado de funciones públicas en el moderno derecho público: la supervisión por los Ombudsmen de los privados a propósito del nuevo papel del Defensor catalán. PRADPI.

Prieto Sanchís, L. (1990). Estudios sobre derechos fundamentales. Debate. pp. 103109.

Ramiro Avilés, M. (2015). Discriminación por razón del VIH: los casos de la clínica legal en 2015. CESIDA

Rubio Llorente, F. (1997). "Los derechos fundamentales. Evolución, fuentes y titulares en España”. Claves de Razón práctica. p. 3.

Segovia de Arana, J. M. (2000). "Asistencia sanitaria y Seguridad Social en España”. Papeles y memorias de la Real Academia de Ciencias Morales y Políticas. pp.14-25.

Serra Perelló, P. Mansilla Jacas, T. (2018). Drets del col-lectiu LGTBIQ. Diagnosi del Pla de drets humans de Catalunya. Sindic. p.14

Sharma, M., Atri, A. (2011). “Essentials of international health". Jones \& Bartlett Publishers. pp. 391 y ss.

Strable, D. (1990) The financial impact of aids on life insurance. Master Thesis. NorthWestern University. 